\title{
ANALYSIS OF THE MOCK-UP OF A REACTOR CONTAINMENT BUILDING: COMPARISON WITH EXPERIMENTAL RESULTS
}

\author{
S. Jiménez ${ }^{1,2, *}$, A. Cornejo ${ }^{1,2}$, L.G.Barbu ${ }^{1,2}$, S. Oller ${ }^{1,3}$ and A. H. Barbat ${ }^{1,2}$ \\ ${ }^{1}$ Centre Internacional de Mètodes Numèrics en Enginyeria (CIMNE), Campus Norte UPC, 08034 Barcelona, Spain \\ ${ }^{2}$ Universidad Politécnica de Cataluña (UPC), Campus Norte UPC, 08034 Barcelona, Spain \\ ${ }^{3}$ Consejo Nacional y de Investigaciones Científicas y Técnicas (CONICET). Facultad de Ingeniería, Universidad \\ Nacional de Salta, Av. Bolivia 5150, 4400, Salta, Argentina
}

\begin{abstract}
The results of a predictive analysis of the mock-up of a reactor containment building, based on computer numerical simulation, are presented in this paper and compared with the results obtained in the context of the VeRCoRs project during the 2015-2018 experimental campaign. The analysis is based on the Serial-Parallel Rule of Mixtures theory applied on a threedimensional finite element model of the building. All the singular parts of the structure (two buttresses, the main penetrations, the gusset, etc.) and the complete prestressing tendons system are included in the structural model. The non-linear constitutive models used to describe the behaviour of the concrete, reinforcing steel and the tendons are formulated. A description of the Serial-Parallel Rule of Mixtures algorithm is also given. The structural response computed for the successive pressure tests applied on the mock-up are compared with the monitored structural behaviour. Finally, results for a simulation considering the aging of the tendon system during 40 years are shown and discussed.
\end{abstract}

Keywords: reactor containment building, finite element method, post-tensioned concrete, serial-parallel rule of mixtures, composites, viscoelasticity.

\section{Introduction}

The predictive analysis of large scale structures is complex requiring the use of high-level computational tools and experimental results that allow the validation of these numerical studies are not always available. This article is the materialization of an opportunity where both, experimental and numerical results, are obtained and compared for a singular structure, a mockup of a nuclear reactor containment building.

The analysis has been performed in the context of the VeRCoRs (Vérification Réaliste du Confinement des Réacteurs) project organized by the company Électricité de France (EDF) where the behaviour of a 1/3 scale mock-up of a reactor containment building, which can be seen in Figure 1, has been studied [1]. This project is part of the EDF program to study the operability of its units and is focused on the analysis of the behaviour at early age and on the evolution of the leak tightness under the effect of ageing as well as on the behaviour of the structure under severe accident conditions. The results of this article have been obtained as part of the work done for the International Benchmark VeRCoRs 2018 which encompassed 21 groups coming from companies and research groups around the world.

This article presents the predictive analysis results of the mock-up of a reactor containment building. The computational study performed has been based on the Serial-Parallel Rule of Mixtures (S-P RoM from now on) [2, 3, 4, 5, 6, 7] which is a technique used in the analysis of composite materials. A complete description of the problem is included and the obtained numerical results are compared with the experimental records showing a good agreement.

\footnotetext{
* Corresponding author. E-mail address: sjimenez@cimne.upc.edu (S. Jiménez)
} 


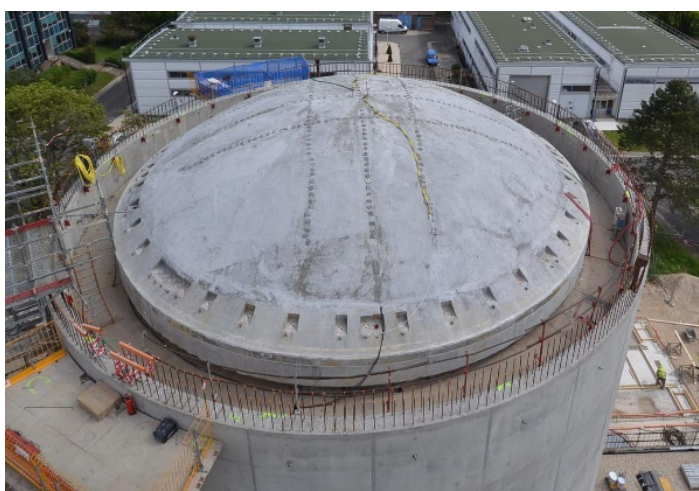

(a)

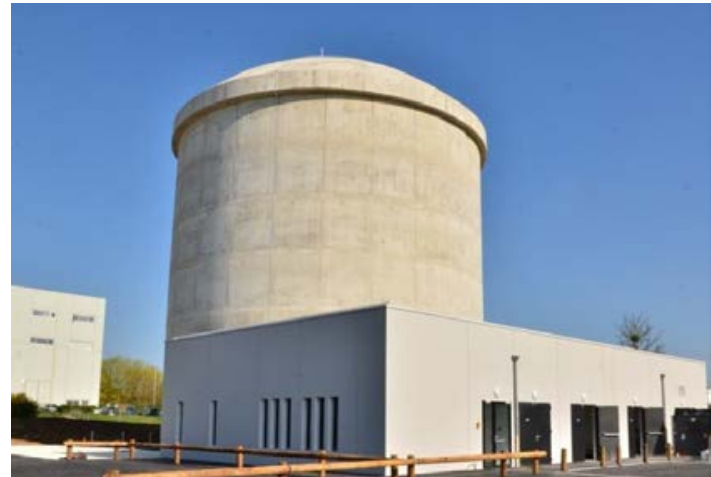

(b)

Figure 1. Reactor containment building analysed in the VeRCoRs Project [1]: (a) Structure during the dome construction; (b) Mock-up overview

\section{Statement of the problem}

\subsection{The benchmark}

The International Benchmark VeRCoRs 2018 is the second organized by EDF in the context of VeRCoRs project. The results shown herein correspond to the work done by the International Centre for Numerical Methods in Engineering (CIMNE) for the topic "Mechanical behaviour of the containment during the pressurization tests" of the Benchmark.

The mechanical behaviour of the containment building is studied over a three-year period. It starts once the containment building is built with the prestressing operation of the tendon system. Then, during the next three years, five pressure tests are performed. In these, the internal pressure is increased up to 4.2 bar (relative internal pressure) and then it is removed, according to the scheme of Figure 2.

The VeRCoRs mock-up is equipped with more than 700 sensors and $2 \mathrm{~km}$ of optic fibre cables that capture continuously the strains evolution in the whole structure (raft, gusset, cylinder, hatches, buttresses and dome, which can be seen in Figure 3). These measurements are compared with the values obtained from the numerical analysis performed and are included in the results section.

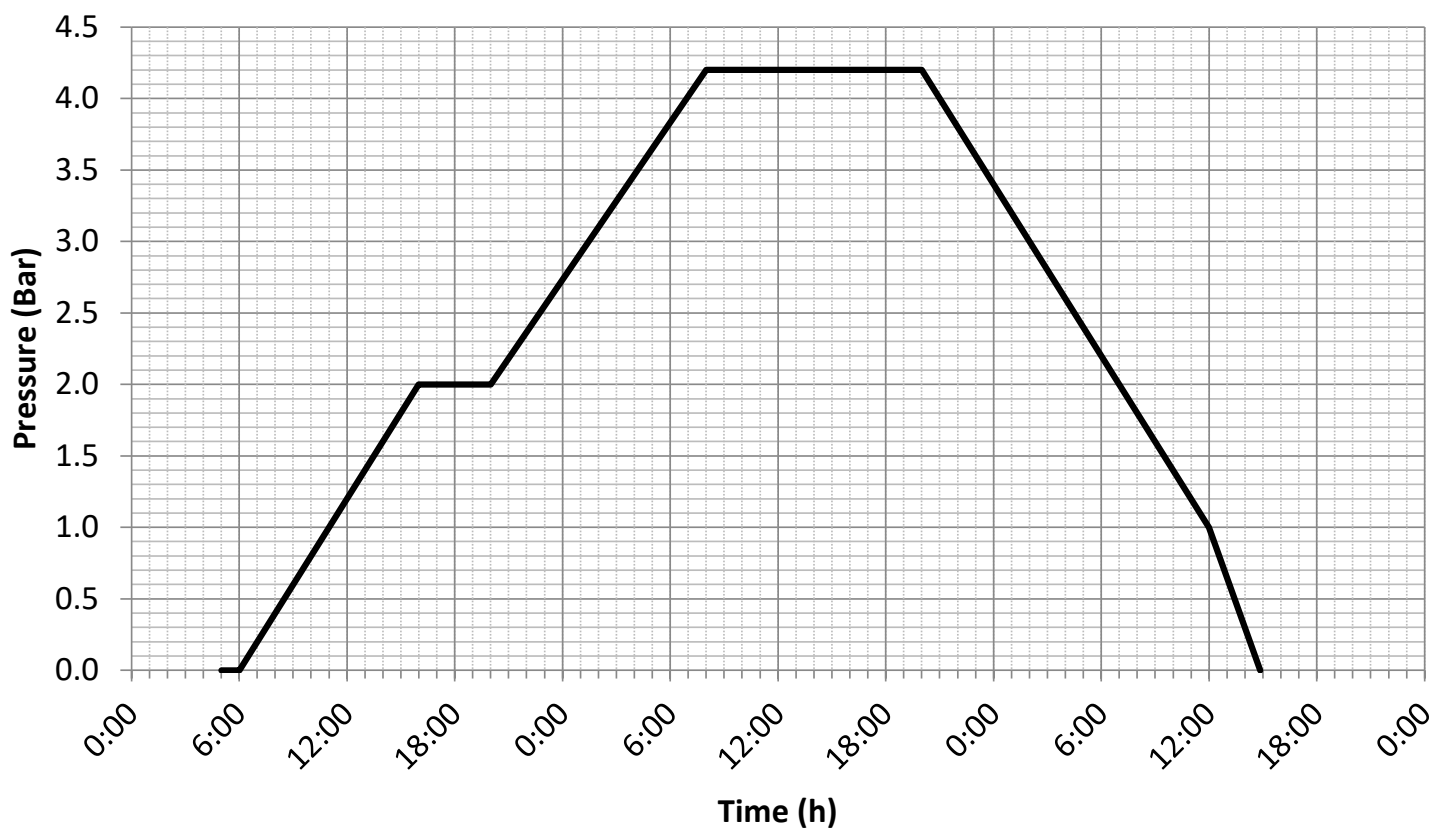

Figure 2 Normalised pressure test evolution 


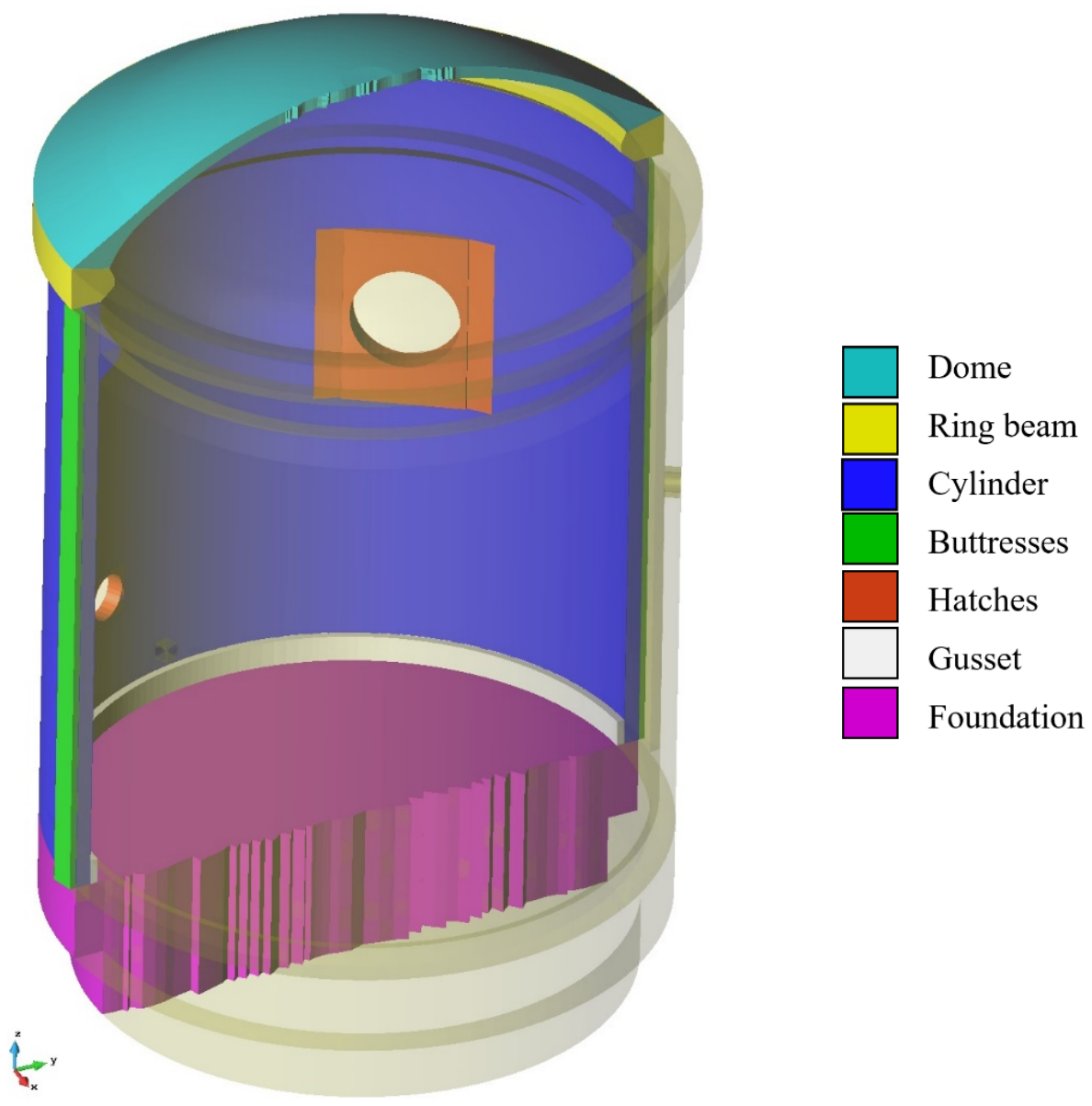

Figure 3 Main parts of the studied reactor containment building mock-up

\subsection{The structure}

The analysed structure is a mock-up of a reactor containment building scaled $1 / 3$ that has been built at EDF Lab Les Renardières near Paris (France). It is a double wall containment building with two vertical buttresses and a ring beam which stiffens the structure. The dimensions of the scaled structure are:

- Height from the gusset to the top: $20.79 \mathrm{~m}$.

- Internal radius of the cylinder: $7.30 \mathrm{~m}$.

- Thickness of the cylinder: $0.4 \mathrm{~m}$.

- Internal radius of the dome (tore): $2.67 \mathrm{~m}$.

- Internal radius of the dome (centre): $10.67 \mathrm{~m}$.

- Thickness of the dome: $0.30 \mathrm{~m}$.

- Free volume inside the containment: $3,160 \mathrm{~m}^{3}$.

Double walled structures are adopted for those reactor containment buildings in which there is no internal liner. In those cases, the external wall is usually made of reinforced concrete and has no structural purpose. This is the case of the studied structure, where the space between the walls is used for leakage control purposes and other monitoring operations.

Obviously, the internal wall is the one that has to withstand the inner pressure and that has been studied in detail. This inner containment is prestressed by means of 295 tendons, classified in four families: horizontal, vertical, dome and gamma tendons, which can be seen in Figure 4. Each tendon is made of $4 \mathrm{~T} 15$ strands and has been tensioned up to $1488 \mathrm{MPa}$ at the active extremities before the anchorage slip. 

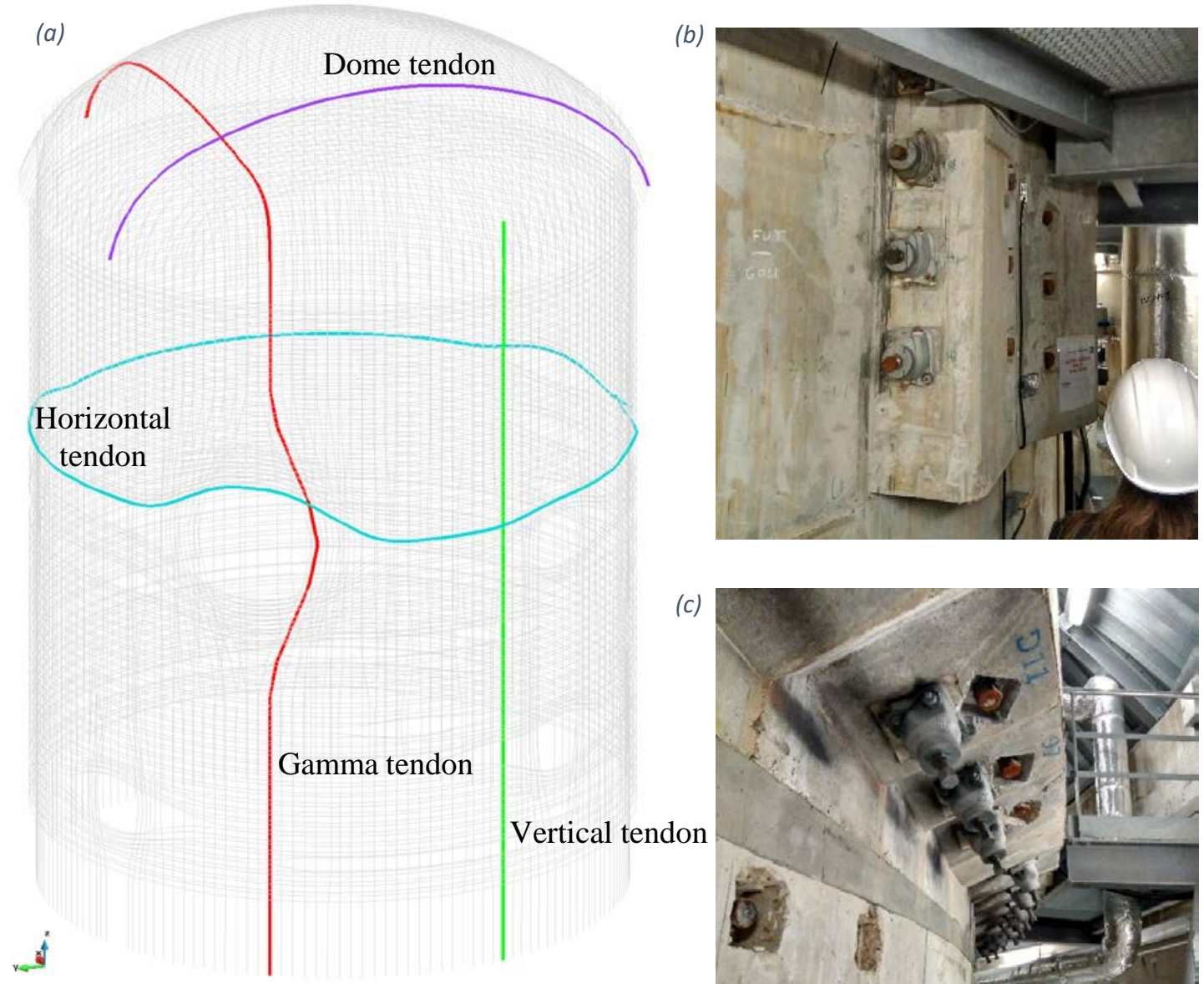

(c)

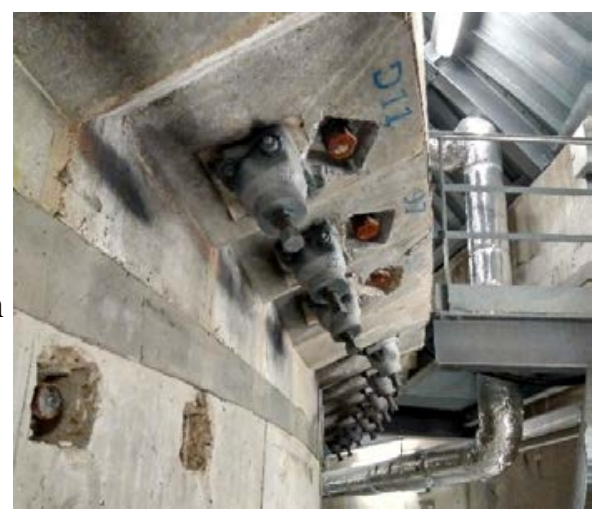

Figure 4 Tendons in the reactor containment building, overview and details: (a) Tendon system of the containment building; (b) Anchorage area of horizontal tendons; (c) Anchorage area of dome and gamma tendons

\section{Strategy of analysis}

A non-linear algorithm for composite materials is used in order to analyse the behaviour of the mock-up of the containment building, which has been modelled using a 3D finite element mesh. Moreover, since the pre-stressed concrete is a composite material, a constitutive model manager for different simple materials (prestressing steel, reinforcing steel and concrete) is required in order to simulate the effect of each material in the composite. This algorithm is implemented in the PLastic Crack dynamic (PLCd) [8] code.

The behaviour of these simple materials is responsible for the main nonlinearities in the analysis, which are mainly constitutive [9]. This means that the relation between the strains and stresses in the material is non-linear and therefore, the constitutive models chosen for simulating the simple materials must include these effects. For concrete, for example, a model has been used which includes the phenomena of damage, simulated by means of its stiffness degradation due to nonadmissible stress levels $[2,3,6,7,10,11]$. And for the case of prestressing steel, the stress relaxation phenomena, that takes place along time due to its intrinsic viscosity, has been simulated using the generalised Maxwell viscoelastic model [2, 3, 7, 10]. These constitutive models do not account for other phenomena like creep or instantaneous prestressing losses and thus, these have been considered in an uncoupled way. Finally, isotropic elasticity [10] has been used to describe the behaviour of reinforcing steel, because this material remains in the elastic domain while the containment is subjected to the existing loads.

As one can see in Figure 3, the geometry of the containment is not symmetrical due to the presence of buttresses and several penetrations in the walls and to the non-uniform distribution of the reinforcing and pre-stressing steel (Figure 4 a) which originates a non-symmetrical distribution 
of stresses. In the 3D finite element analysis performed, all these geometrical aspects have been considered.

As far as the applied loads are concerned, the model has been subjected to its own weight, to the prestressing loads and to the five pressure tests performed during the years 2015 - 2018. On the other hand, thermal and hydric effects are not considered in the analysis as these type of loads are not supported yet by the constitutive laws implemented in PLCd. The model of the containment has been developed using the geometry and the information about the prestressing loads in the tendons which was provided by EDF, ensuring the correlation between the real structure and the model.

\section{Computational model}

\subsection{Constitutive modelling of the composite materials}

The methodology used to simulate the composite materials of the containment is the before mentioned S-P RoM [2, 3, 4, 5, 6, 7]. This formulation is usually applied for the study of fiberreinforced composite materials and it defines two different behaviours in terms of the strain and the stress states of the composite constituent materials, i.e. an iso-strain condition in the parallel direction, usually the fibre direction and in this case the tendon direction in each finite element, and an iso-stress condition in the serial direction, usually the remaining directions. In order to state the stress equilibrium and the strain compatibility, one must describe analytically these two behaviours:

$$
\begin{array}{ll}
\text { Parallel behaviour: } & \left\{\begin{array}{l}
{ }^{c} \varepsilon_{P}={ }^{f} \varepsilon_{P}={ }^{m} \varepsilon_{P} \\
{ }^{c} \sigma_{P}={ }^{f} k \cdot{ }^{f} \sigma_{P}+{ }^{m} k \cdot{ }^{m} \sigma_{P}
\end{array}\right. \\
\text { Serial behaviour: } \quad\left\{\begin{array}{l}
{ }^{c} \varepsilon_{S}={ }^{f} k \cdot{ }^{f} \varepsilon_{S}+{ }^{m} k \cdot{ }^{m} \varepsilon_{S} \\
{ }^{c} \sigma_{S}={ }^{f} \sigma_{S}={ }^{m} \sigma_{S}
\end{array}\right.
\end{array}
$$

where superscripts $c, m$ and $f$ stand for composite (prestressed concrete), matrix (concrete) and fibre (tendons), respectively and $k$ corresponds to the volume fraction coefficient of each constituent of the composite.

A Newton-Raphson algorithm is used in order to solve this system of equations, in which the serial strain of the matrix has been considered as the independent variable and the equilibrium in the serial stresses of the matrix and fibre is achieved iterating.

A more detailed explanation of the methodology can be found in $[2,4,5,6]$, including a description of the complete procedure followed in order to apply the tendons' pre-stressing loads upon the composite material.

\subsection{Constitutive modelling of the concrete}

In order to simulate the stiffness degradation of the concrete due to the applied loads, an isotropic damage model [11] is used. In this model, the material degradation occurs in all directions uniformly and it only depends on one scalar damage variable $d$. Thus, the constitutive equation of the isotropic damage model is

$$
\boldsymbol{\sigma}=\boldsymbol{\sigma}_{\mathbf{0}}(1-d)=(1-d) \mathbf{C}_{\mathbf{0}} \boldsymbol{\varepsilon}
$$

where $d$ is the internal variable of damage, $\boldsymbol{\sigma}$ is Cauchy's stress tensor, $\boldsymbol{\sigma}_{\mathbf{0}}$ is the predictor Cauchy's stress tensor measured in an equivalent non-damaged space, $\mathbf{C}_{\mathbf{0}}$ is the constitutive elastic tensor and $\boldsymbol{\varepsilon}$ is the Green-Lagrange strain tensor.

This model requires the definition of a damage threshold criterion. The objective of this criterion is to make a distinction between the elastic and the non-linear behaviours, in which the stress level is inside or outside the elastic domain, respectively. In this study, the Modified Mohr-Coulomb yield surface has been used [10] for the definition of the elastic domain as well as an exponential softening law for computing the damage [10, 11]: 


$$
d\left(\boldsymbol{\sigma}_{\mathbf{0}}\right)=1-\frac{\tau}{f\left(\boldsymbol{\sigma}_{\mathbf{0}}\right)} \cdot \exp \left(A \cdot\left(1-\frac{f\left(\boldsymbol{\sigma}_{\mathbf{0}}\right)}{\tau}\right)\right)
$$

where $f\left(\boldsymbol{\sigma}_{\mathbf{0}}\right)$ is the uniaxial stress computed according to the Modified Mohr-Coulomb yield surface [10,12], $\tau$ is the mechanical threshold that is related to the material yield strength and $A$ is a parameter that depends on the fracture energy. A more detailed explanation of the used damage model can be seen in references $[10,13,14]$.

As stated in section 3, this constitutive model does not include the creep effects. Therefore, it has been necessary to account for the phenomena in an uncoupled way in order to describe properly the results. This has been done by means of a viscoelastic model (Kelvin model) [10] which allowed to characterize the progressive strain variation in concrete due to creep.

\subsection{Constitutive modelling of the prestressing steel}

A generalized Maxwell model $[2,7,10]$ has been used for the prestressing steel characterisation. This is a viscoelastic model used to describe the rheological behaviour of materials, controlled by two main variables: the time delay and a viscous parameter. Figure 5 shows a scheme of the general behaviour of the model, in which it can be observed how the stress level is reduced with time while the strain remains constant.

The stress integration in the multiaxial case is performed as follows [10]:

$$
\begin{aligned}
& {\left[\sigma_{i j}\right]^{t+\Delta t}=\left[\sigma_{i j}\right]^{t} \cdot \mathrm{e}^{-(\Delta t) / r_{1}}-\mathrm{C}_{i j k l}\left[\varepsilon_{k l}\right]^{t} \cdot \mathrm{e}^{-(\Delta t) / r_{1}}\left[1+\frac{\mathrm{C}_{1}}{\mathrm{C}_{0} \xi} \frac{\Delta t}{2}\right]} \\
& +\mathrm{C}_{i j k l}\left[\varepsilon_{k l}\right]^{t+\Delta t} \cdot\left[1-\frac{\mathrm{C}_{1}}{\mathrm{C}_{0} \xi} \frac{\Delta t}{2}\right]
\end{aligned}
$$

where $\xi_{1}$ is the viscosity and the coefficients $C_{0}$ and $C_{1}$ are obtained once the stress levels of the material $\sigma(t=0)$ and $\sigma(t=\infty)$ are known. In this way, if the load induces a constant strain rate, the model accounts for the stress relaxation of the material along time $[2,10]$.

\subsection{Pre-stressing load modelling}

In order to apply the pre-stressing load, an innovative procedure regarding the automatic generation of composite materials has been conducted. This procedure only needs the finite element mesh used in the calculation and a linear description of the geometry of the steel tendons. The intersections of the linear elements (steel tendons) with the finite element mesh are calculated. Once the coordinates of the intersections are known for all the hexahedras in the mesh, the volumetric participations of the pre-stressing steel in the concrete and the orientation of the fibre are computed. Thus, each tendon is defined as a sequence of composite materials in the finite element mesh as can be seen in Figure 6 for the case of a gamma tendon.

Once these operations have been done for all the finite elements intersected by tendons, the SPRoM imposes the strain corresponding to the prestressing force of the tendons oriented in the longitudinal direction of the steel fibre simulating, in this way, the pre-stressing effect upon the structure. Further details can be found in reference $[2,7]$.

\section{Model of the structure}

\subsection{Geometry and material properties}

Figure 3 shows an overview of the model used in the analysis of the containment building. In addition to the structure geometry and the layout of the prestressing system, EDF provided exhaustive information referring to the material properties of the structure (concrete, reinforcing and prestressing steel). All this information has been properly assigned to the numerical model to reproduce the correct behaviour of each of the singular parts of the structure. With this purpose, seven different regions have been defined, as shown in Figure 3, and different concrete material 
properties and/or different reinforcing steel volumetric participations have been assigned (Table 1).

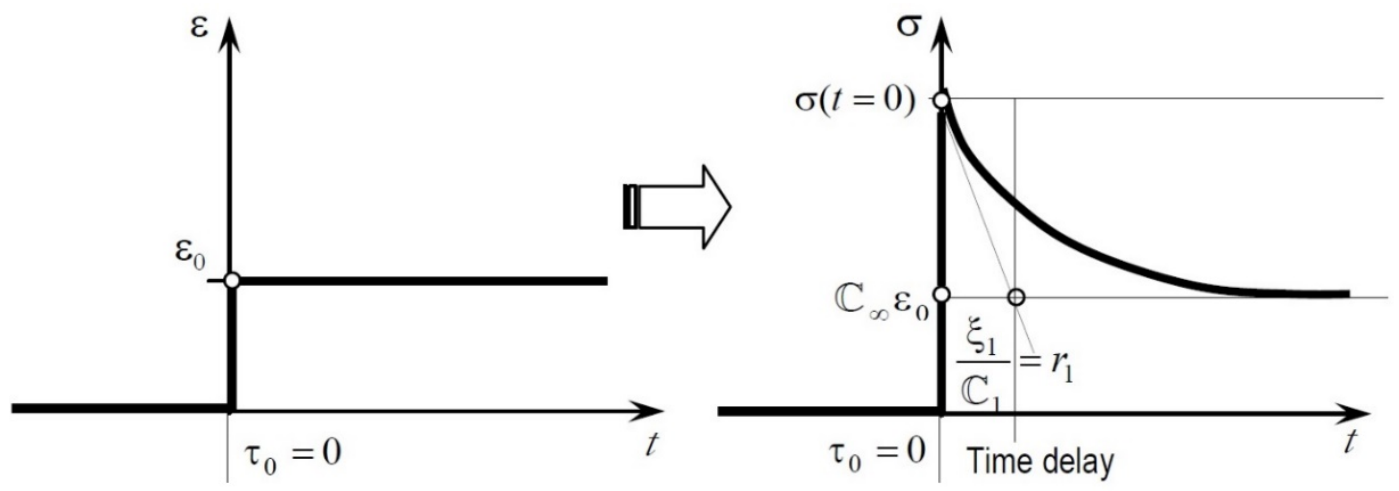

Figure 5 Uniaxial generalized Maxwell model [10]

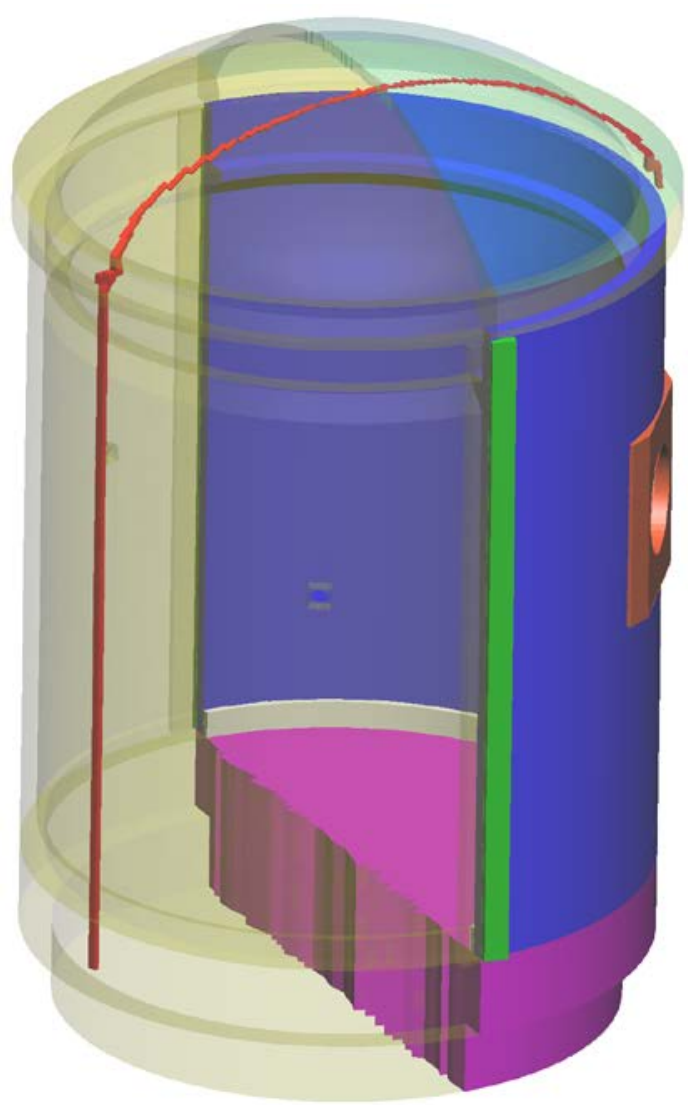

Figure 6 Hexahedras in the finite element mesh intersected by a gamma tendon during the generation of the composite materials. 
Table 1 Concrete and steel material properties used in the numerical model (see Figure 3)

\begin{tabular}{|c|c|c|c|c|c|c|c|}
\hline & \multicolumn{4}{|c|}{ CONCRETE } & \multicolumn{3}{|c|}{ REINFORCING STEEL } \\
\hline & $\begin{array}{c}\text { Young } \\
\text { modulus } \\
\text { [GPa] }\end{array}$ & $\begin{array}{l}\text { Compressive } \\
\text { strength (28 } \\
\text { days) [MPa] }\end{array}$ & $\begin{array}{c}\text { Tensile } \\
\text { strength (28 } \\
\text { days) [MPa] }\end{array}$ & $\begin{array}{l}\text { Density } \\
{[\mathrm{kg} / \mathrm{m} 3]}\end{array}$ & $\begin{array}{c}\text { Yield } \\
\text { strength } \\
\text { [MPa] }\end{array}$ & $\begin{array}{c}\text { Young } \\
\text { modulus } \\
\text { [GPa] }\end{array}$ & $\begin{array}{c}\text { Volumetric } \\
\text { participation } \\
{[\%]}\end{array}$ \\
\hline Cylinder & 34.26 & 48.68 & 4.36 & 2395 & 500 & 200 & 1.00 \\
\hline Gusset & 34.26 & 48.68 & 4.36 & 2395 & 500 & 200 & 1.00 \\
\hline $\begin{array}{l}\text { Equipment and } \\
\text { Personal hatches }\end{array}$ & 34.26 & 48.68 & 4.36 & 2395 & 500 & 200 & 1.50 \\
\hline Buttresses & 39.20 & 48.68 & 4.36 & 2395 & 500 & 200 & 1.50 \\
\hline Dome & 32.51 & 40.90 & 4.20 & 2350 & 500 & 200 & 1.50 \\
\hline Ring beam & 34.26 & 56.90 & 4.50 & 2430 & 500 & 200 & 2.00 \\
\hline Foundation & 33.26 & 38.50 & 3.60 & 2360 & 500 & 200 & 2.00 \\
\hline
\end{tabular}

The tendons have a cross section of $556 \mathrm{~mm}^{2}$ and are made of a material with a Young's modulus of $190 \mathrm{GPa}$ and with a tensile strength of $1860 \mathrm{MPa}$. This information has been used in the definition of the generalized Maxwell model that controls the rheological behaviour of the tendon system as well as for the generation of the composite materials (see section 4.3).

The initial strain values of the tendons, used to simulate the prestressing effect, have been obtained from the average stress of each tendon. Therefore, it has been necessary to compute the real stress distribution at the moment that the structure becomes functional by taking into account the immediate force losses $[15,16]$ occurring during the prestressing operations and during the anchorage phases, i.e. all the instantaneous losses except those originated by the instantaneous deformation of concrete, which are calculated implicitly during the finite element analysis.

The losses due to friction $\left(\Delta P_{f}\right)[15]$ are calculated as:

$$
\Delta P_{f}(x)=P_{0}\left(1-e^{-(\mu \theta+k x)}\right)
$$

where $P_{0}$ is the force applied at the active end, $\mu$ is the friction coefficient, $k$ is the Wobble coefficient, $\theta$ is the sum of the angular displacement and $x$ is the distance along the tendon.

The losses at the anchorage $\left(\Delta P_{a}\right)$ are:

$$
\Delta P_{a}(x)=\frac{a E_{p} A_{p}}{l_{p}}=P_{0}\left(1-e^{-(\mu \theta+k x)}\right)
$$

where the same force loss function has been considered as for friction losses (Eq. 6), $l_{p}$ is the tendon length where the losses originated by the anchorage operation are located, $a$ is the pull-in at wedge blocking, $E_{p}$ is the prestressing steel Young modulus and $A_{p}$ is the tendon area $[15,17$, $18]$.

The results obtained depend not only on the geometry and on the material properties, but also on the location of the active ends. In fact, all the tendons in the studied structure have been prestressed from both ends except the vertical tendons that have been tensioned from the lower one.

Figure 7 shows the final stress distribution for two tendons of the containment computed through the equations (6) and (7) (purple line) and the mean stress distribution (green line) required for the calculation of the initial strain values used in the numerical analysis. 

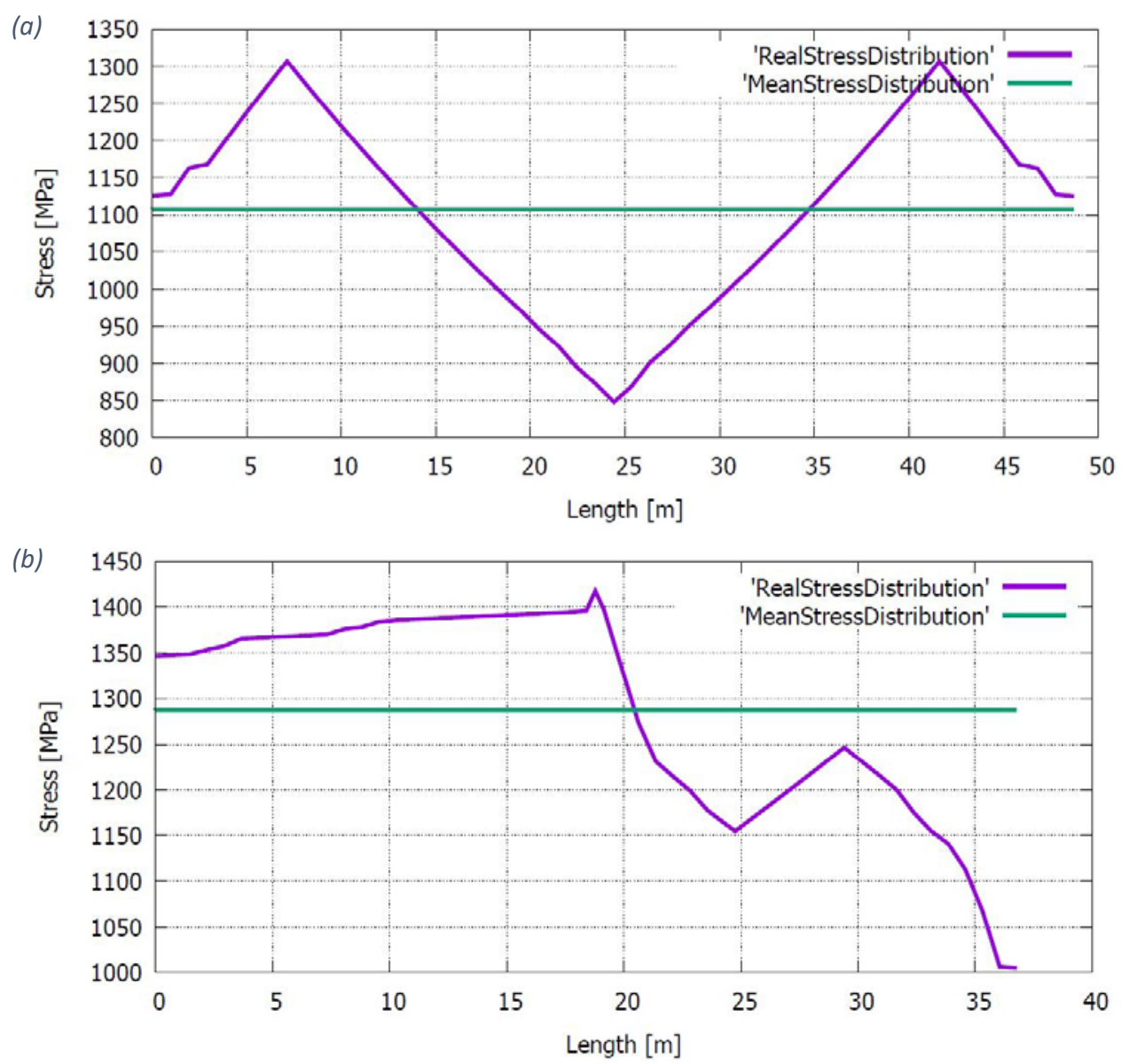

Figure 7 Real/Mean stress distribution of two tendons in the containment building: (a) Horizontal46 tendon stress distribution considering instantaneous losses (see Figure 4a)); (b) Gamma155 tendon stress distribution considering instantaneous losses (see Figure 4 a)

\subsection{Finite element mesh}

Figure 8 shows the finite element mesh used in the analysis. It has been generated using the software called GiD [19] and it has 199,600 8-nodded hexahedras with 8 integration points.

A total of 40,696 composite materials are obtained intersecting the tendons with the finite element mesh. It is worth mentioning that these composite materials are composed of three simple materials: concrete, reinforcing steel and prestressing steel and contain the required information for the application of the S-P RoM algorithm.

\subsection{Calibration of the model}

Only minor changes involving the material properties or the reinforcing steel volumetric participations were susceptible to be made to the model as the main data of the problem was already provided by EDF. According to this, some sensitivity tests were performed, which showed no significant variation in the results. Among them, different feasible volumetric participations have been considered for the reinforcing steel at different regions of the containment moving from values of $0.8 \%$ up to $3.0 \%$ in dome or from $0.6 \%$ to $1.5 \%$ in the cylinder. In addition to this, variations in the concrete Young modulus have also been considered throughout the structure modifying the initial value $20 \%$. This indicates that using this approach while studying the containment building, the veracity of the obtained results totally depends on the adjustment of the constitutive models to the real phenomena that takes place and not so much on the adjustment of the material properties.

Therefore, the calibration information provided by EDF has been used to validate rather than to calibrate the model. This information consists in displacement measurements obtained through a system of pendulums and invar wires (Figure 9), which are shown in Table 2 together with the 
results obtained by the numerical simulation.

(a)

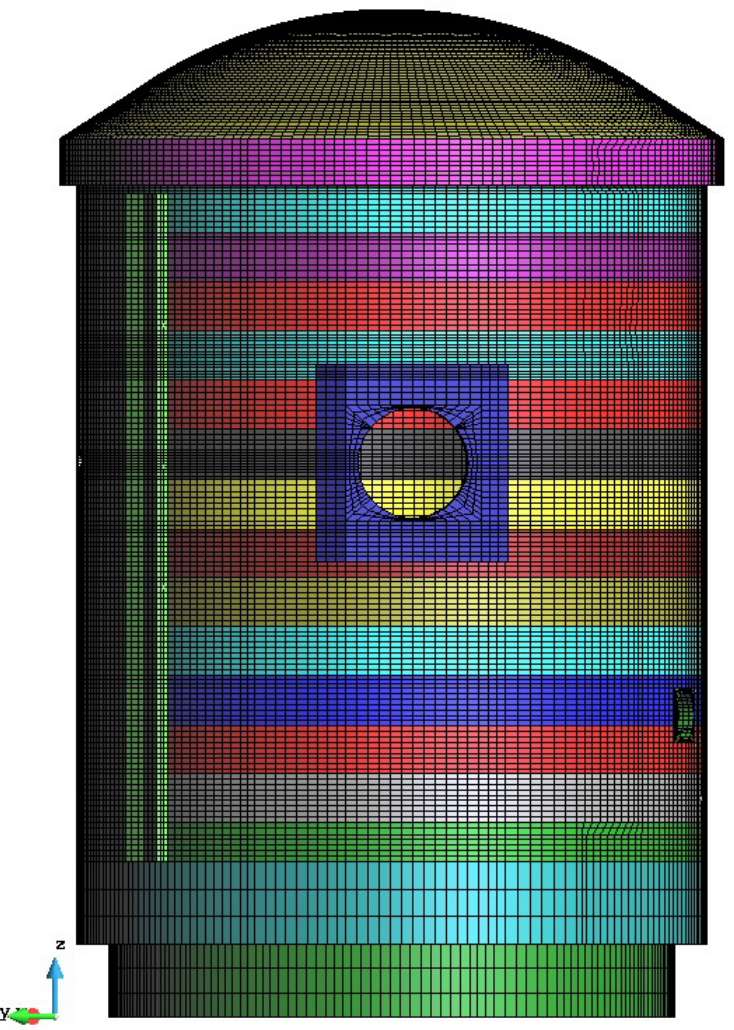

$(b)$

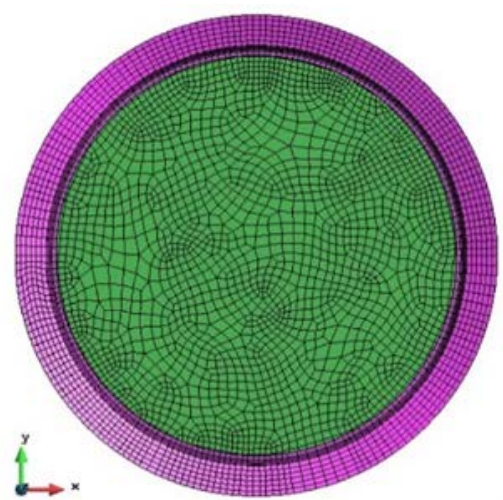

(c)

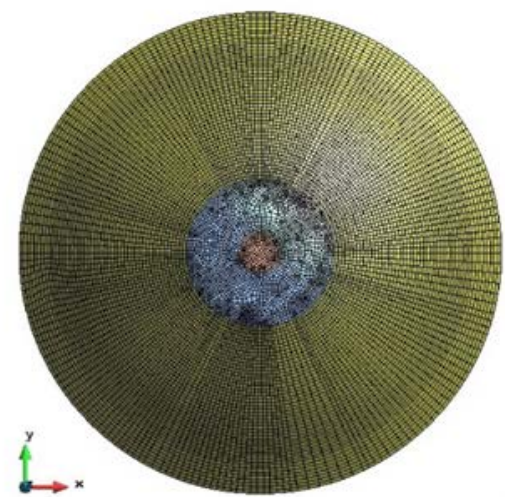

Figure 8 Finite element mesh: (a) General view; (b) Foundation and ring beam view; (c) Dome view

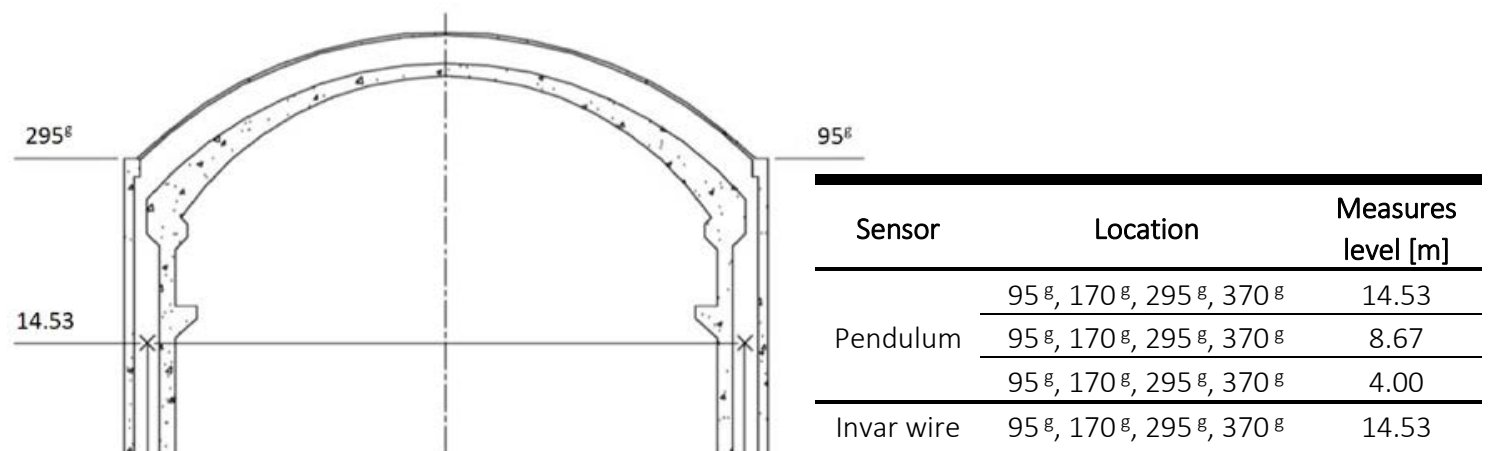

8.67

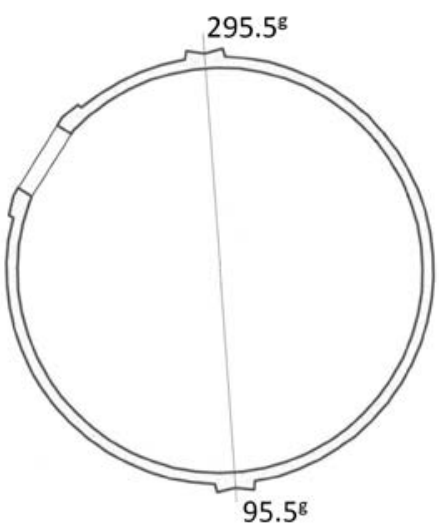

Figure 9 Pendulum and invar position in containment building used for measuring diameter and height variations [1] 


\begin{tabular}{|c|c|c|c|c|}
\hline \multirow[b]{3}{*}{ Level } & \multicolumn{4}{|c|}{ Diameter variation under 4.2 bar } \\
\hline & \multicolumn{2}{|c|}{$1^{\text {st }}$ pressure test } & \multicolumn{2}{|c|}{$2^{\text {nd }}$ pressure test } \\
\hline & $\begin{array}{l}\text { Experimental } \\
\text { results }[\mathrm{mm}]\end{array}$ & $\begin{array}{c}\text { Simulation } \\
\text { results }[\mathrm{mm}]\end{array}$ & $\begin{array}{c}\text { Experimental results } \\
{[\mathrm{mm}]}\end{array}$ & $\begin{array}{c}\text { Simulation results } \\
{[\mathrm{mm}]}\end{array}$ \\
\hline Lower, 4m & 3.3 & 3.17 & 3.3 & 3.18 \\
\hline $\begin{array}{c}\text { Intermediate, } \\
8.67 \mathrm{~m} \\
\end{array}$ & 3.0 & 3.11 & 3.1 & 3.12 \\
\hline \multirow[t]{5}{*}{$\begin{array}{l}\text { Upper, } \\
\text { 14.53m }\end{array}$} & 1.0 & 1.29 & 1.1 & 1.30 \\
\hline & \multicolumn{4}{|c|}{ Height variation under 4.2 bar } \\
\hline & \multicolumn{2}{|c|}{$1^{\text {st }}$ pressure test } & \multicolumn{2}{|c|}{$2^{\text {nd }}$ pressure test } \\
\hline & $\begin{array}{l}\text { Experimental } \\
\text { results }[\mathrm{mm}]\end{array}$ & $\begin{array}{c}\text { Simulation } \\
\text { results [mm] }\end{array}$ & $\begin{array}{c}\text { Experimental results } \\
{[\mathrm{mm}]}\end{array}$ & $\begin{array}{c}\text { Simulation results } \\
{[\mathrm{mm}]}\end{array}$ \\
\hline & 1.45 & 1.18 & 1.50 & 1.18 \\
\hline
\end{tabular}

Experimental results in Table 2 were obtained during the first and second pressure tests through the system of 4 pendulums and 4 invar wires. Pendulums were used for the measurement of diameter variations while height variations were measured through the invar wires. Simulation results were computed by tracking the displacements in those nodes from the finite element mesh which geometrically coincide with the positions of the installed sensors.

Small variations can be observed between the experimental and the simulation results, showing the same tendency from the first pressure test to the second one. In addition to this, the numerical model is stiffer than the real structure at the lower instrumented level but this progressively changes while moving up to the upper instrumented level where the behaviour is reversed and the numerical model becomes more flexible than the mock-up. This could be mitigated considering non-uniform material properties along the height for the concrete used in the cylinder.

\section{Results}

Displacements, The PLCD [8] code has been used to carry out the finite element analysis and for the pre-processing operations, GiD software [19] has been used as well as for post-processing the results obtained from the simulations. Displacements, strains and stresses for each integration point of the finite element mesh, as well as the evolution of the damage internal variable, d, have been computed for the whole period of analysis. In this section, the obtained results are compared with the experimental ones recorded in the framework of the VeRCoRs project and provided to the Benchmark participants after the submission of their results.

Figure 10 shows the location of some selected sensors which measure vertical (V), tangential (T), radial and/or meridian strains. These are:

- E1_CENTRE_95. Centred raft sensor measuring strains in a direction aligned with the buttresses.

- F2EV. Gusset sensor measuring strains in vertical direction.

- P1ET. Cylinder sensor measuring strains in a direction tangent to the cylinder.

- I1 94. Centred dome sensor measuring strains in a direction aligned with the buttresses.

These sensors made continuous measurements during the project extension. Therefore, it has been possible to plot these values recorded on site, together with the strain results obtained with the numerical analysis (Figures 11 to 14). All these charts have been obtained following the same criteria, setting the reference date for strains $(\varepsilon=0)$ at the end of the prestressing stage as the study has been focused on the analysis of the structural behaviour at the time when the pressure tests were performed. This also explains why simulation results are plotted starting at the beginning of the first pressure test (November 2015) although the numerical simulation covers the whole period of analysis including the construction and the prestressing stages. 
The information plotted in these charts should be studied by dividing it in two: the strain evolution during pressure tests (PT's) and the strain evolution at the time gap between these tests. In fact, they can be easily identified in the figures by knowing the time when they were performed:

- PT1: 04-06 November 2015,

- PT2: 25-29 January 2016,

- PT3: 14-21 March 2017,

- PT4: 21-23 March 2017,

- PT5: 02-03 April 2018,

and because, in most of the sensors, the pressure tests generate a sudden variation in the strain state, as shown in Figures 13 and 14. The results obtained with the numerical simulation for these pressure tests are similar to the measured ones and only small discrepancies can be observed. The model shows a stiffer behaviour of the cylinder (Figure 13), while the gusset (Figure 12) and the dome (Figure 14) response show a more flexible behaviour than the one observed in the real structure.

Important differences can be observed between the two data for the time period between the pressure tests. These variations are evident in all the inter-pressure test periods except for the period between PT1 and PT2. After this pressure test, the only significant change is due to the start of the ambient air heating operation. This process involves the injection of heated air inside the containment during the time lapse between pressure tests PT2 and PT3 and PT4 and PT5. This explains the sudden variations of the monitored strains and the discrepancies with the numerical simulation, in which the thermal effects have not been included. In addition to this, depending on the local morphology of the mesh, the strains can change considerably from one element to another and thus, another source of errors of the strains obtained from the numerical simulation is due to the approximation with which the sensors are placed in the finite element mesh. Finally, some minor error can be attributed to differences between material properties from real structure and those assigned at each part of the numerical model as stated in section 5.3.

Stress distribution in the concrete of the containment building is shown in Figures 15 to 18. These images have been obtained right before the internal pressure is applied and at the time when the applied pressure reaches its maximum for the first and the fifth pressure tests. Therefore, the figures can help to identify the effect induced by the applied internal pressure and the rheological effects in the stress distribution. Two images are included for each event, showing the maximum principal stress and the minimum principal stress in the whole containment.

In all the scenarios, it can be observed a generalized compression state of the structure originated by the tendon system. Moreover, maximum tension levels are localized at the area of the personal airlock at the cylinder and at the mid-region at the dome, while maximum compressions take place at the gusset area and at the top of the dome.

The changes introduced by the internal pressure in the containment building can be observed comparing Figures 15 and 18 with Figures 16 and 17. These correspond to a generalized reduction in the compression state of the structure while the containment building is being pressurized. In addition to this, comparing now the values obtained for PT1 (Figures 15 and 16) and PT5 (Figures 17 and 18), it can be observed that the successive application of the pressure tests does not generate significant changes in the stress distribution neither before the beginning of the pressure tests nor for the instant where the internal pressure is maximum. However, the observable changes in stress values can be attributed to the progressive variation of the damage in concrete accentuated during the pressure tests (Figure 19) and to the gradual decay of the prestressing forces with time. This can be deduced studying the evolution of these variables along the analysed period as it can be seen in Figures 19 to 23. 


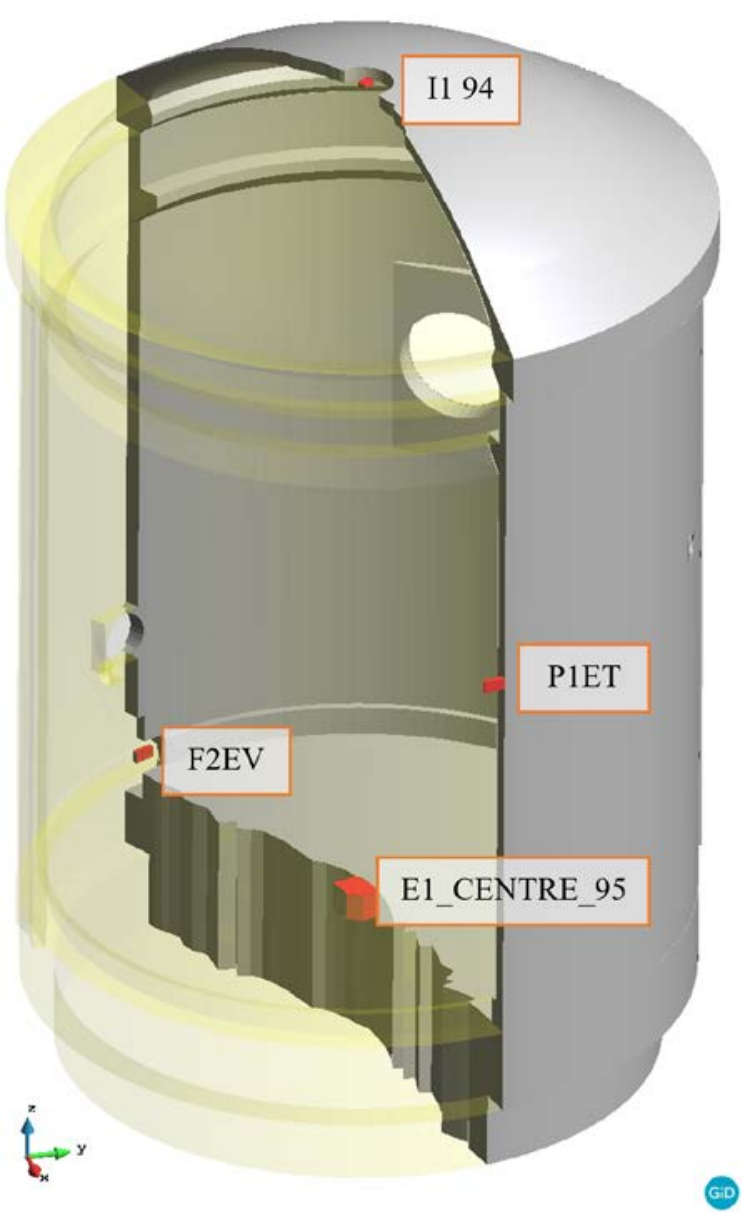

Figure 10 Location of the sensors used in the study

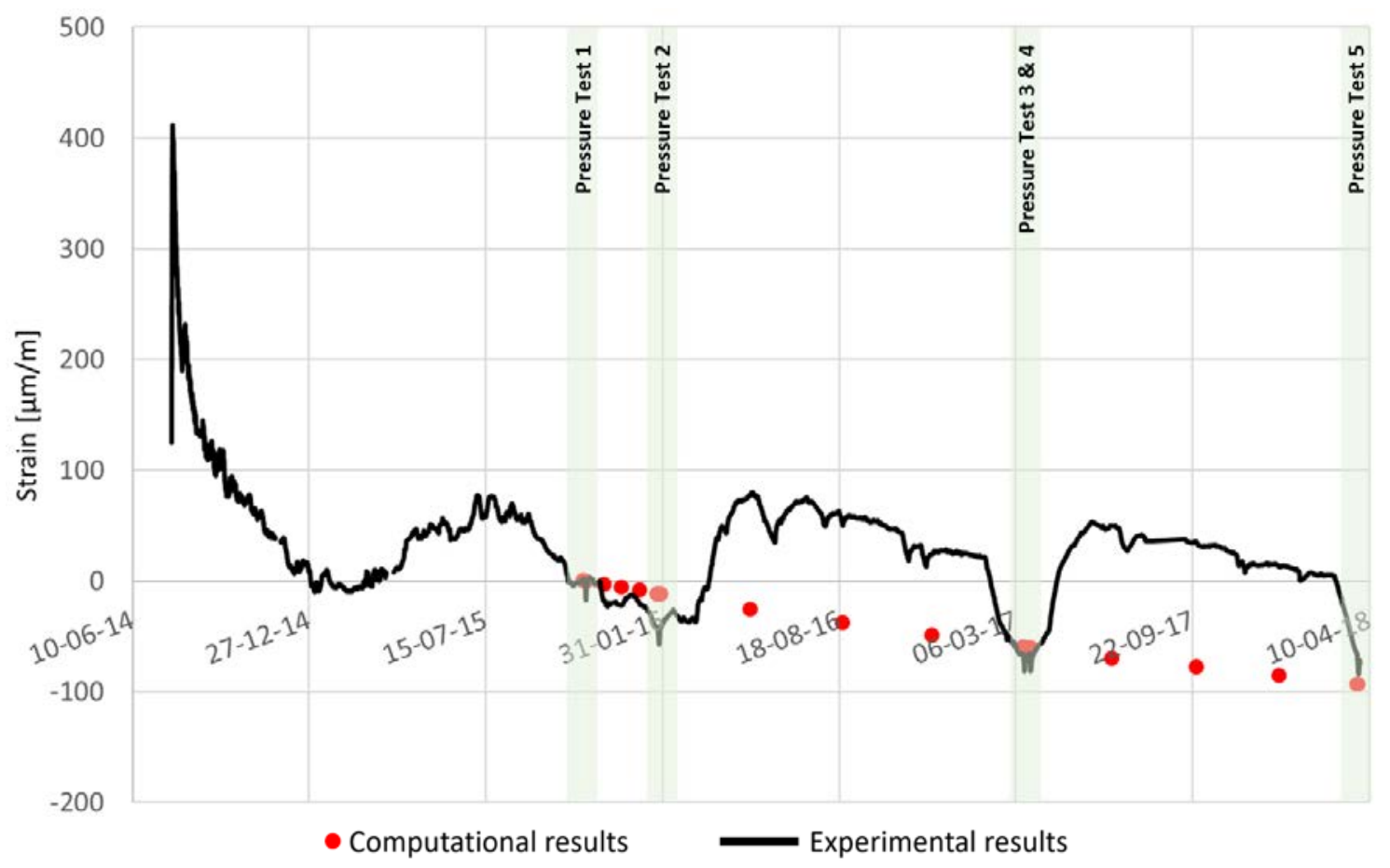

Figure 11 Relative strains evolution at raft measured by the sensor E1_CENTRE_95 during the whole period of analysis (black line) [1] and the corresponding strains obtained numerically starting at the first pressure test (red dots). 


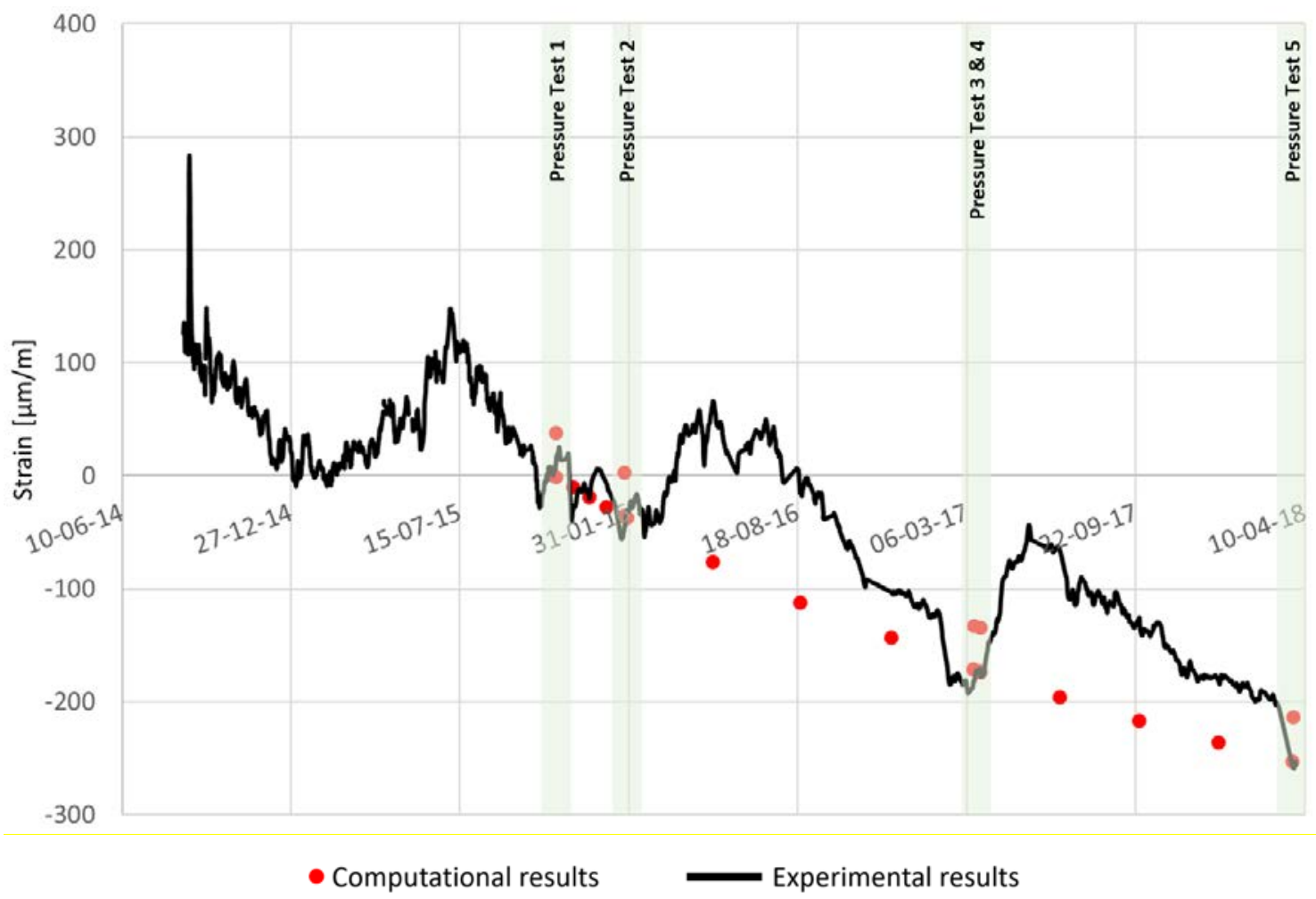

Figure 12 Relative strains evolution at gusset measured by the sensor F2EV during the whole period of analysis (black line) [1] and the corresponding strains obtained numerically starting at the first pressure test (red dots).

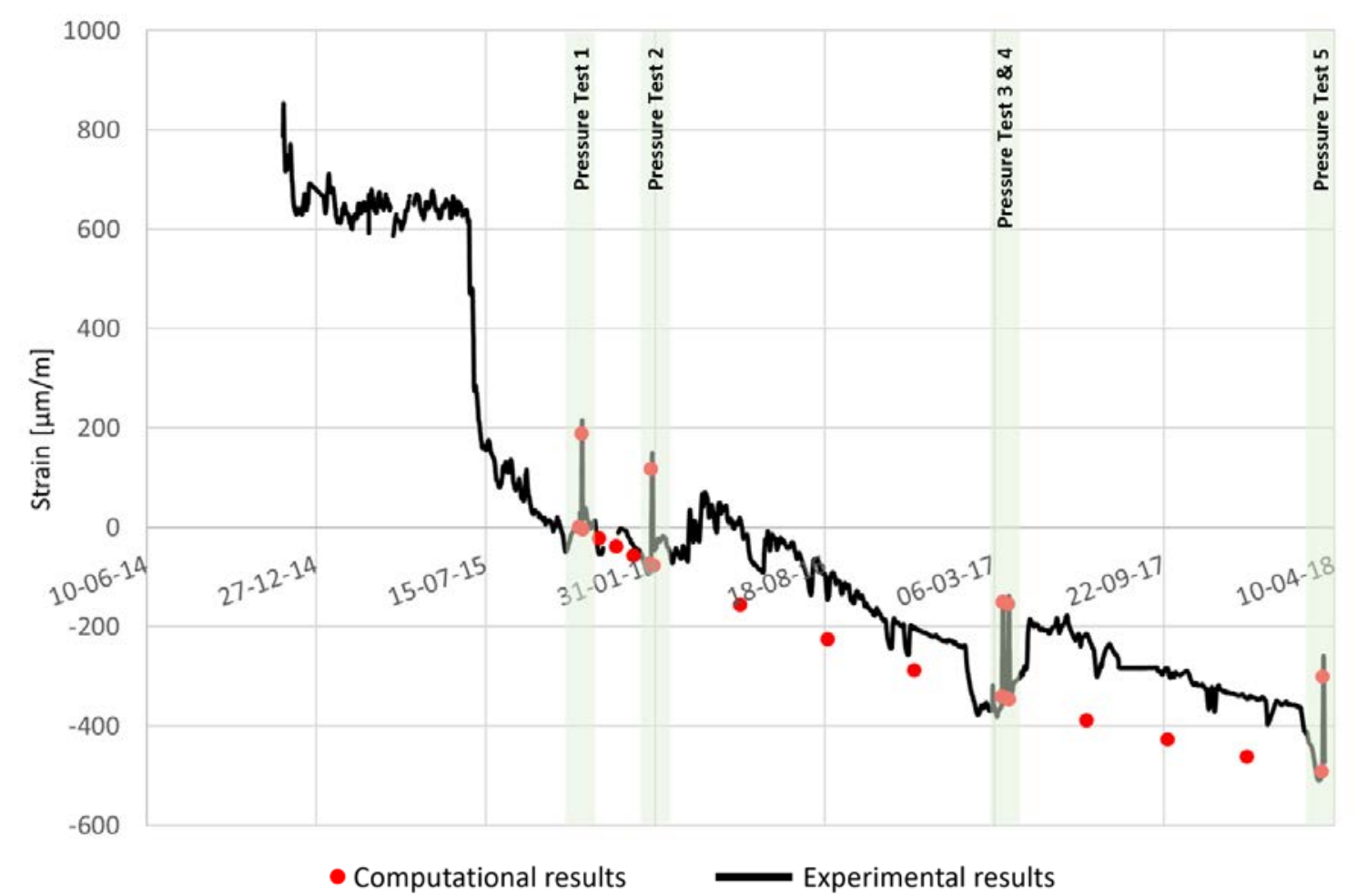

Figure 13 Relative strains evolution at cylinder measured by the sensor P1ET during the whole period of analysis (black line) [1] and the corresponding strains obtained numerically starting at the first pressure test (red dots). 


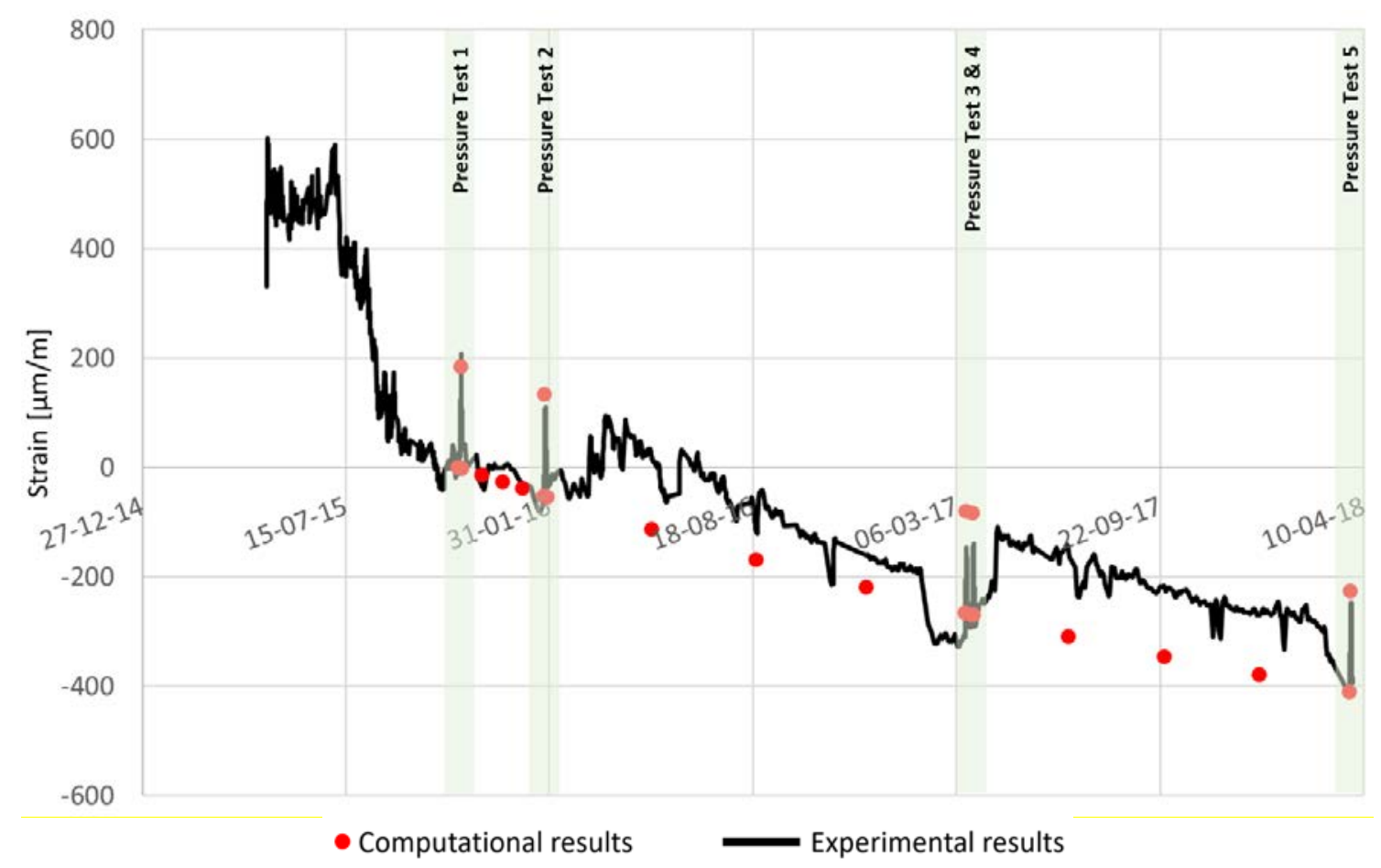

Figure 14 Relative strains evolution at dome measured by the sensor 1194 during the whole period of analysis (black line) [1] and the corresponding strains obtained numerically starting at the first pressure test (red dots).
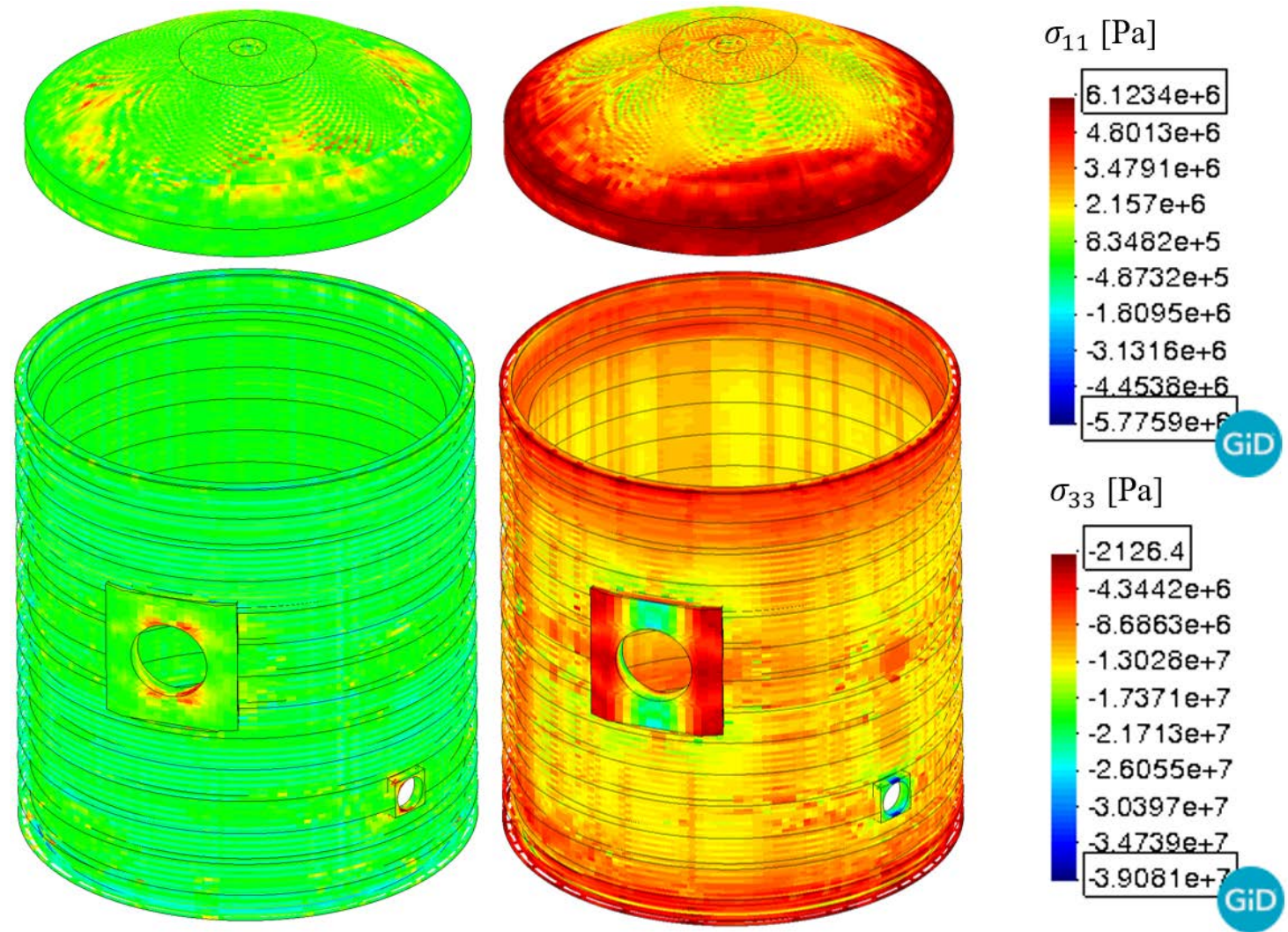

Figure 15 Stress distribution in concrete at the beginning of the PT1. Maximum principal stress, $\sigma_{11}$ (left) and minimum principal stress, $\sigma_{33}$ (right) 

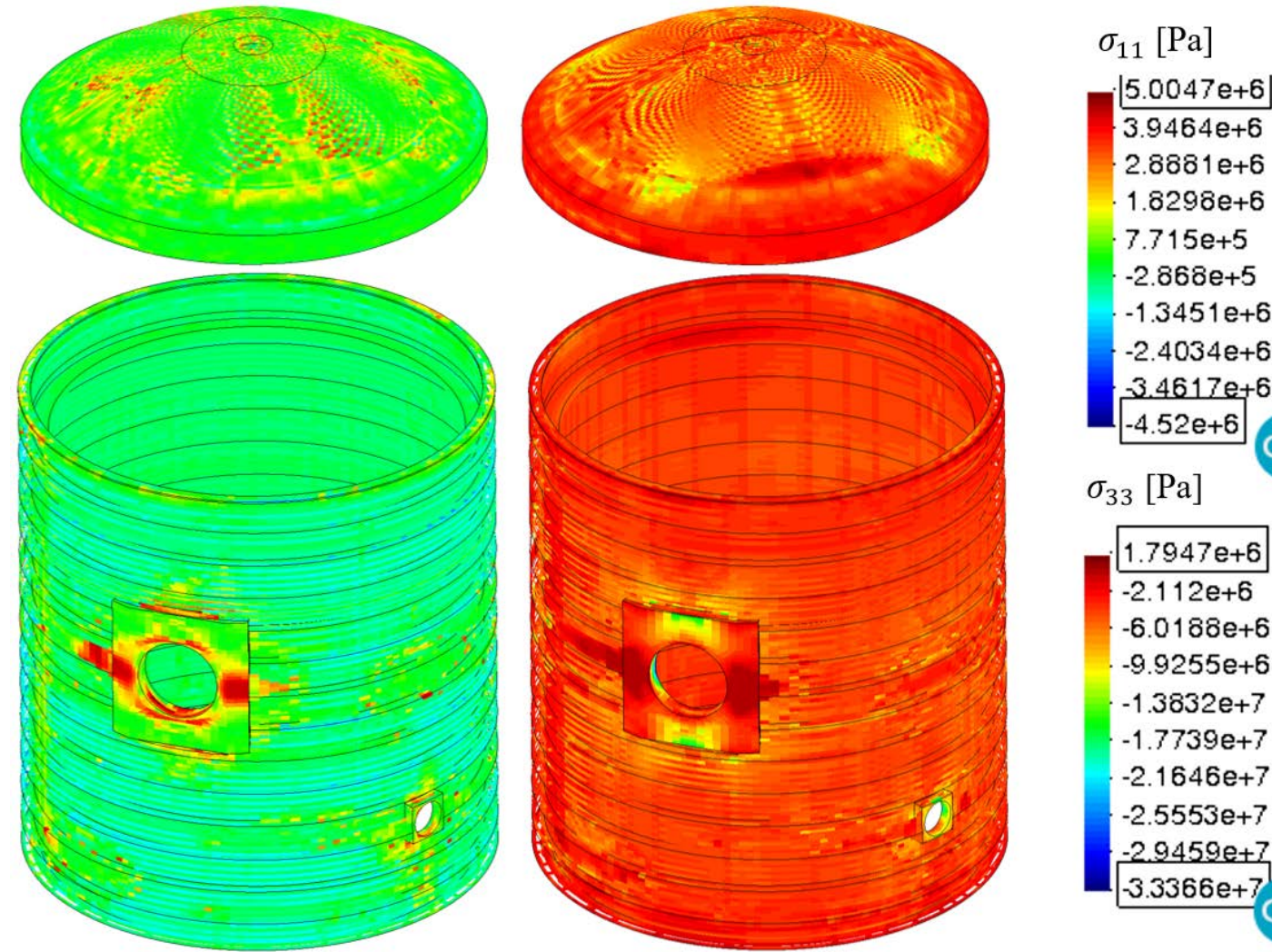

$\sigma_{33}[\mathrm{~Pa}]$

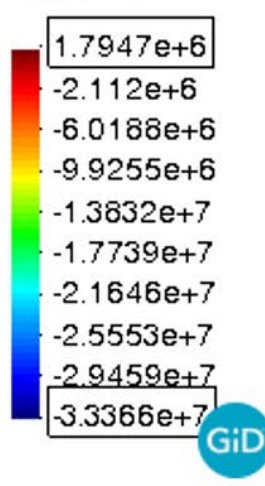

Figure 16 Stress distribution in concrete at the maximum pressure instant of the PT1. Maximum principal stress, $\sigma_{11}$ (left) and minimum principal stress, $\sigma_{33}$ (right)
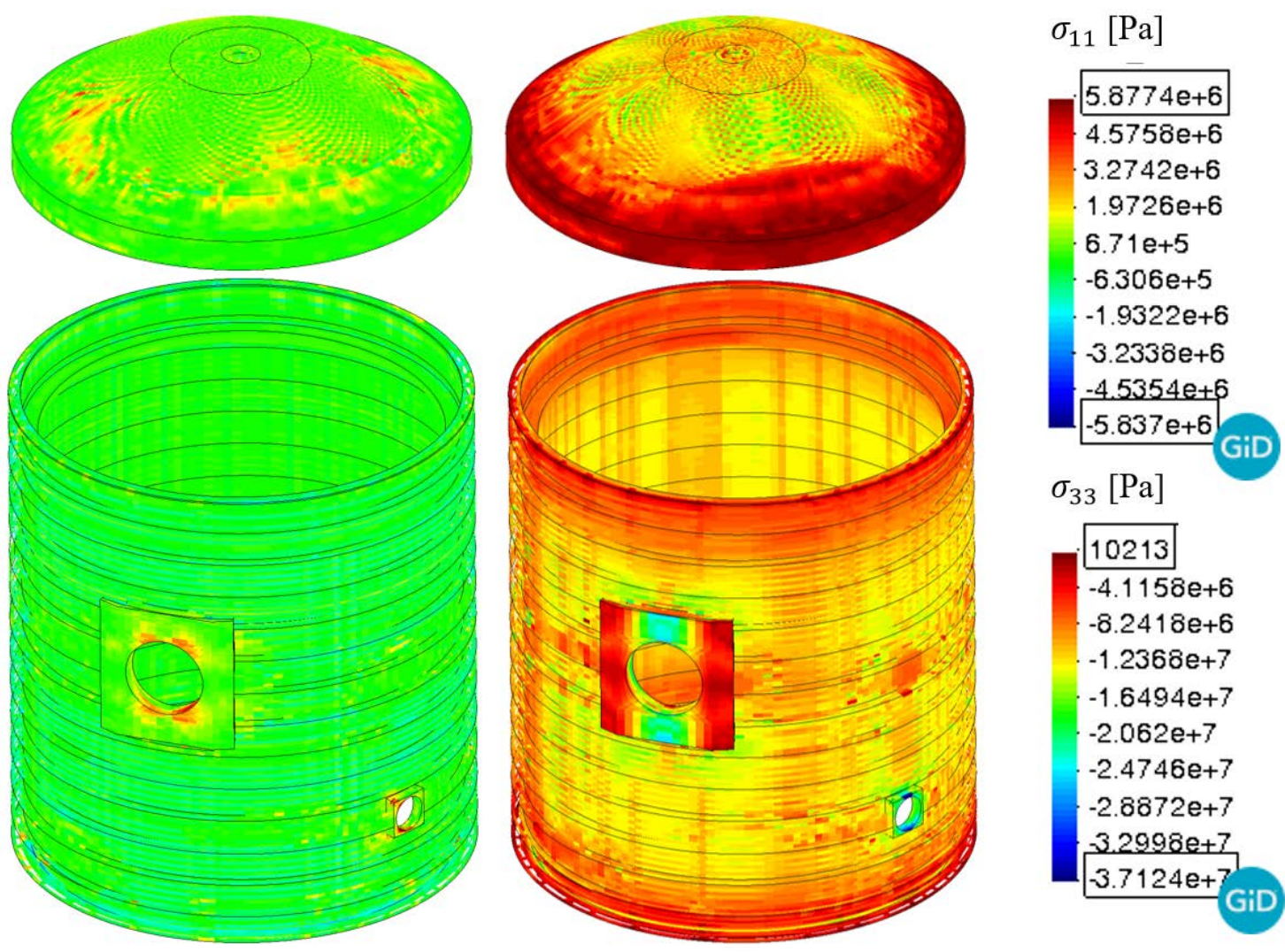

$\sigma_{33}[\mathrm{~Pa}]$

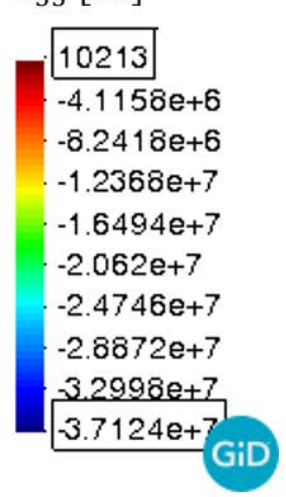

Figure 17 Stress distribution in concrete at the beginning of the PT5. Maximum principal stress, $\sigma_{11}$ (left) and minimum principal stress, $\sigma_{33}$ (right) 

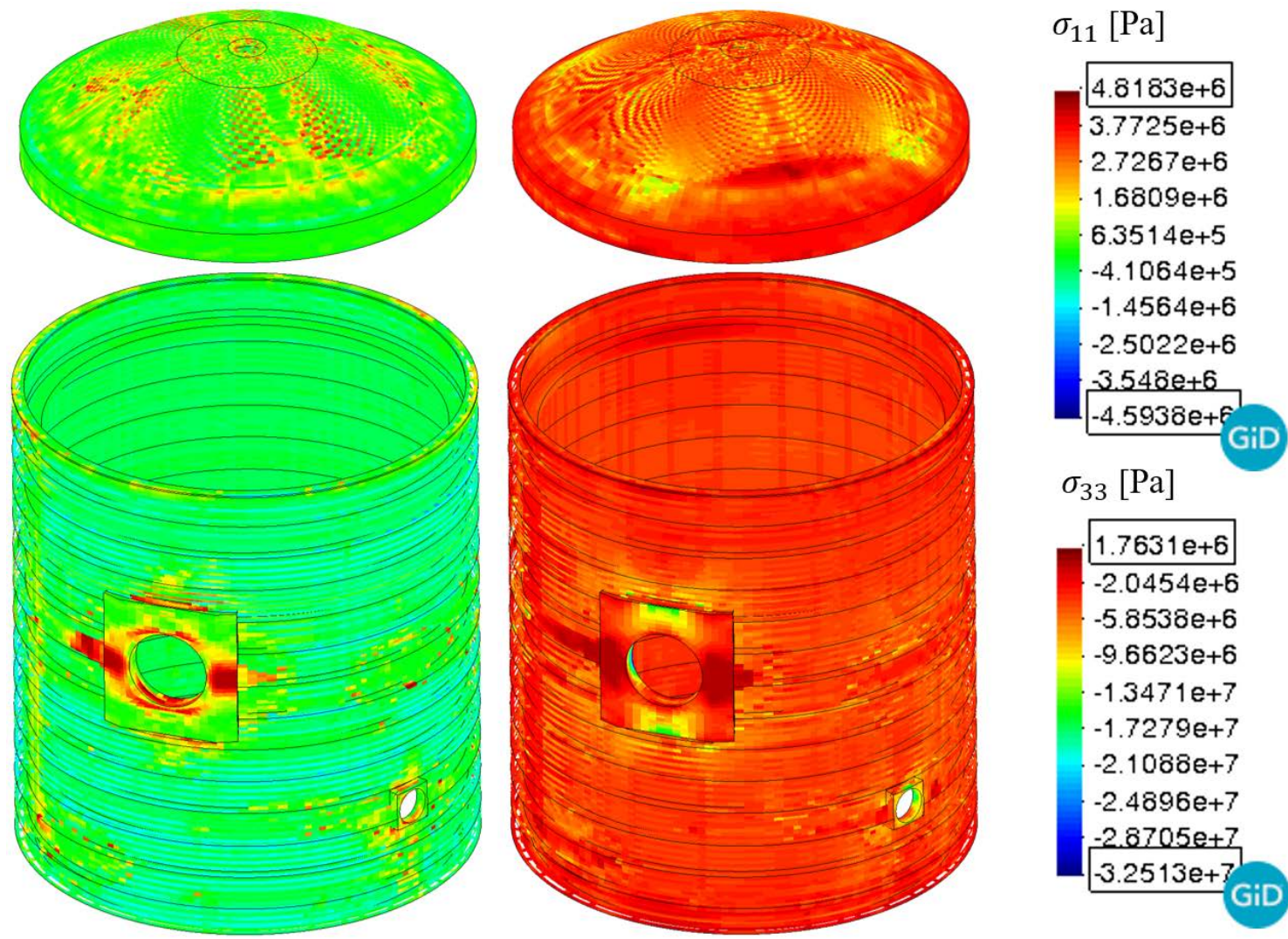

Figure 18 Stress distribution in concrete at the maximum pressure instant of the PT5. Maximum principal stress, $\sigma_{11}$ (left) and minimum principal stress, $\sigma_{33}$ (right)

Figure 19 shows the evolution of damage internal variable at three instants during the period of analysis: for the instant when the structure becomes fully functional (beginning of PT1); for the instant with maximum internal pressure during PT1; and at the beginning of PT5.

These images allow to study the impact that the successive operations performed during the structure's life have on its integrity. The effect of the prestressing operation (Figure 19 a), the effect of the first pressure test on the structure (Figure 19 a to Figure $19 \mathrm{~b}$ ) and the consequences of rheological effects and the successive pressure tests on the containment building (Figure $19 \mathrm{c}$ ) can be observed. After the prestressing stage, a generalized damage state at the dome can be detected, probably due to the flat shape of this area. Although the reached damage values are low at this stage, they increase during the PT1. Along this pressure test, new damaged areas appear at the surrounding area of the hatches but, after this, no more significant changes are observed, neither in the distribution of damage or in the reached values.

The images cover the whole range of the damage internal variable, $d$, starting from 0.1 (instead of 0 to filter low values) up to 1 . A value of $d=1$ is never reached and the highest values at the end of the period of analysis (Figure $19 \mathrm{c}$ ), which is the worst scenario, are $d=0.8$. In fact, these are just spurious values occurring in some singular points where the geometry and the finite element mesh can induce some disturbances. The damage internal variable reaches value of 0.30.5 for most of the elements in this scenario. 
(a)

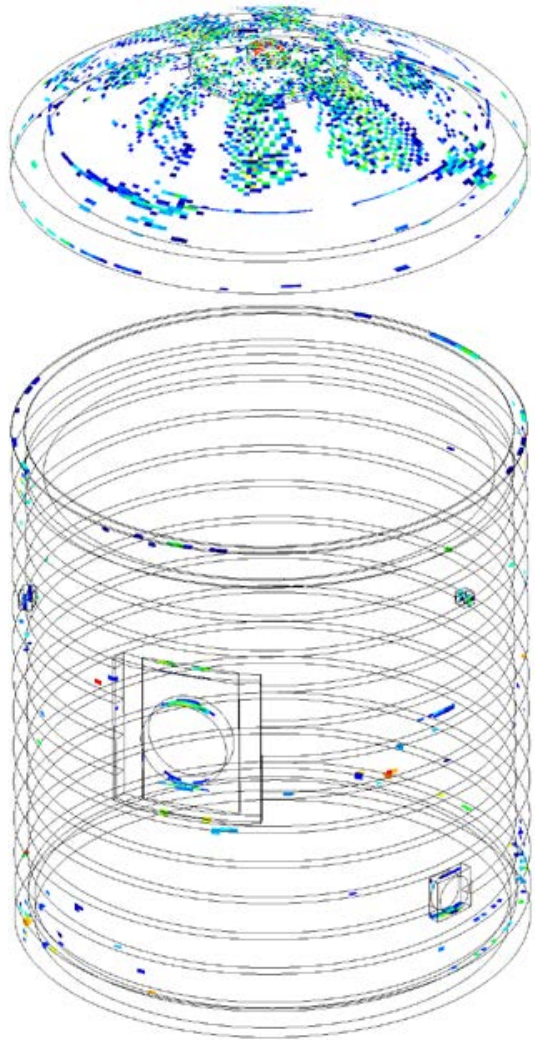

(b)

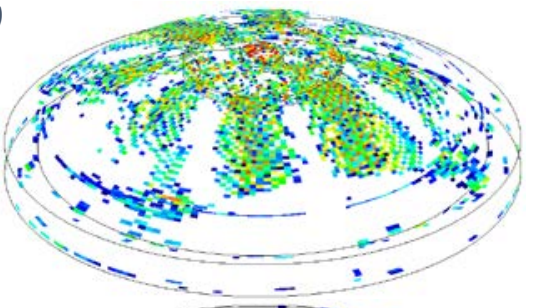

Damage internal variable, $d$
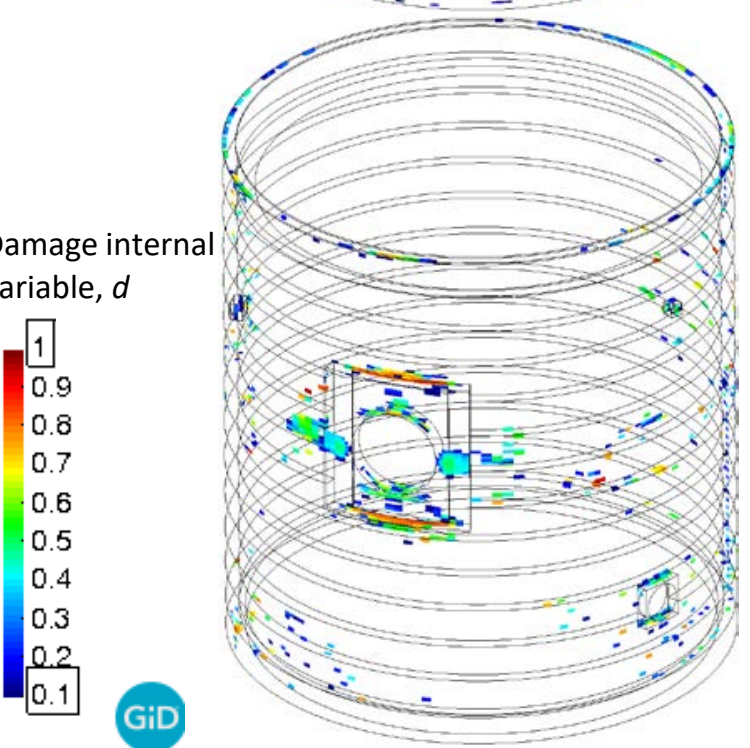

(c)

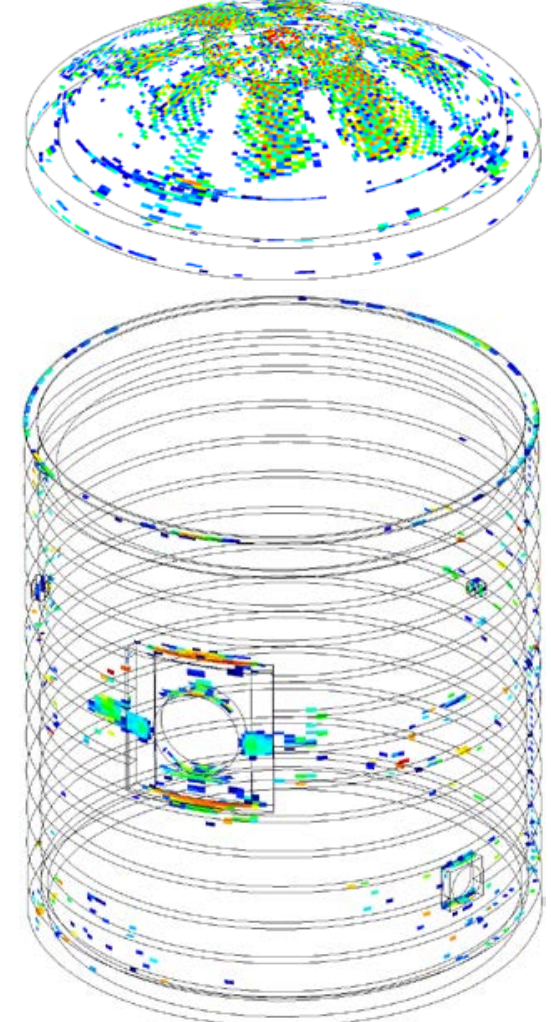

Figure 19 Evolution of the damage internal variable in the containment. (a) Beginning of the PT1; (b) Maximum pressure at the PT1; (c) Beginning of the PT5

Together with the evolution of the damage in the concrete of the structure, the changes in the prestressing forces during the analysed period also affect the containment state. This evolution is of interest for the analysis of containment buildings because it can affect the structural safety and 
it can become a limiting factor of the structure's life. Using an approach based on the S-P RoM, results are obtained for each of the component material of the structure and the stress in the tendons can be computed along the whole period of analysis. As an example, this evolution is shown in Figures 20 and 21 for the vertical and dome tendons, respectively. Each line represents the evolution of the mean longitudinal stress of a tendon.

In all cases, the tendons show a progressive prestressing force loss influenced by the following aspects:

- Pressure tests. The effect of pressure tests can be recognized easily in both charts as sudden changes in the stress state that break the prestressing loss tendency. These tests momentarily increase the stress in the tendons when the internal pressure is applied on the structure.

- Location dependency. For a certain instant, the mean stress level in the tendons of a family, i.e. horizontal, vertical, dome or gamma, can be different from one to another. This fact is more evident in dome tendons (Figure 21) than in vertical tendons (Figure 20) and it can be easily explained when the curves in the charts are related with the position of the tendons in the structure. It can be observed that tendons with higher stresses are those located at stiffer areas, e.g. near the ring beam, while the path of those with a lower stress level crosses more flexible zones of the structure. This phenomenon is also evident for horizontal tendons, where different behaviour can be observed among those tendons located near the ring beam, or near the foundation and those placed in the middle area of the cylinder.

The conclusions that can be derived from the study of the prestressing force evolution are not relevant when the analysed period is too short, but these become much more important when the study is extended to the regular life of a containment building. Therefore, a new analysis extended to 40 years has been performed during which the internal pressure is increased again up to $4.2 \mathrm{bar}$ only at the end of this time period. For this case, Figures 22 and 23 show the prestressing force evolution for vertical and dome tendons. Obviously, decreases in the stress level for each tendon are now significant in comparison with the stress reduction observed in the previous case and, therefore, this aspect should be taken into consideration as the period of analysis is increased. Note that, as the stress reduction becomes more important, it is necessary to better define the Maxwell model parameters that control this evolution in time. For the purpose of the Benchmark this was not required and thus, this phenomenon is presented in the paper qualitatively rather than quantitatively.

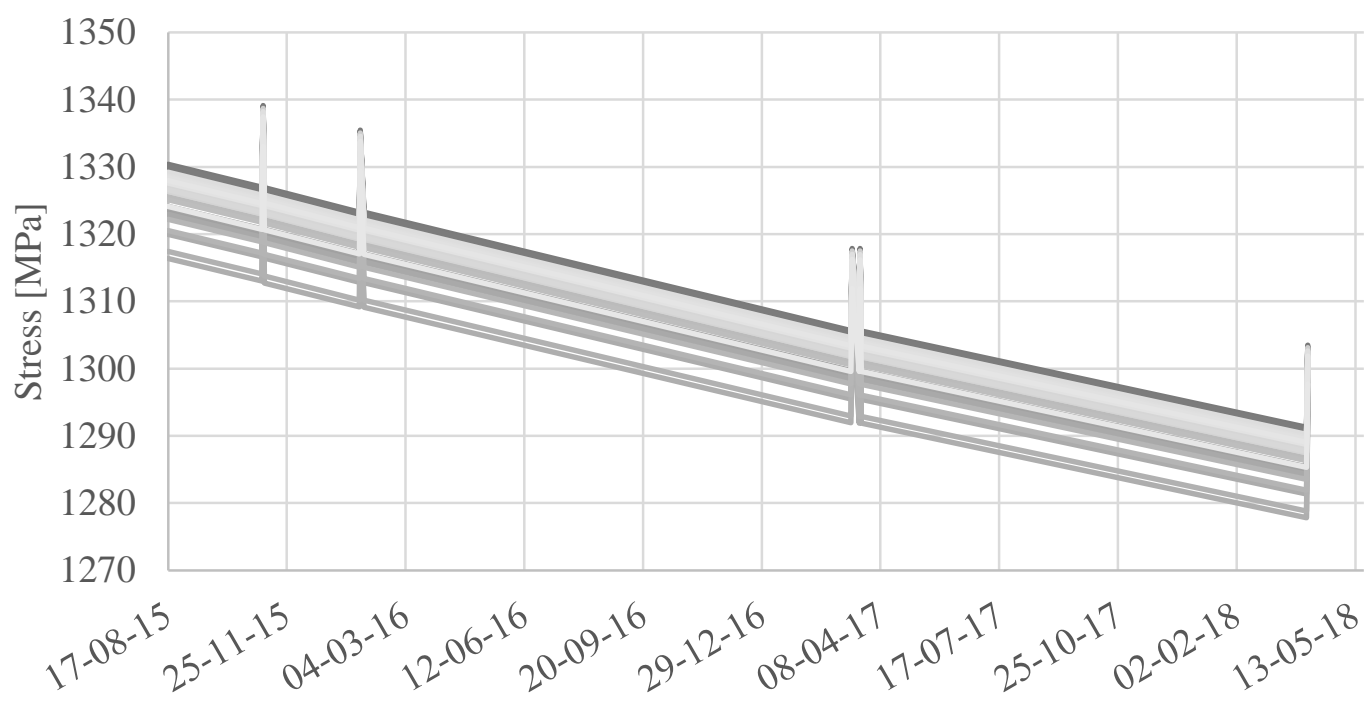

Figure 20 Evolution of the prestressing force in vertical tendons for the 3-year analysis 


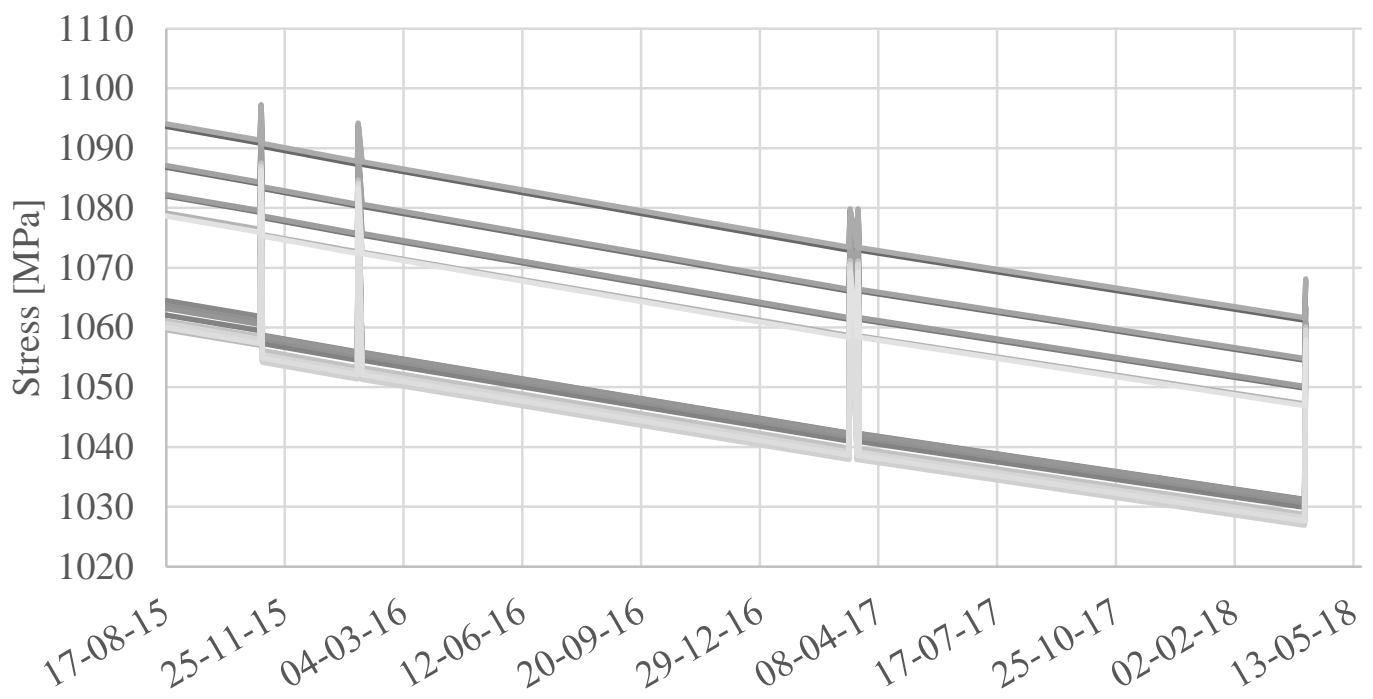

Figure 21 Evolution of the prestressing force in dome tendons for the 3-year analysis

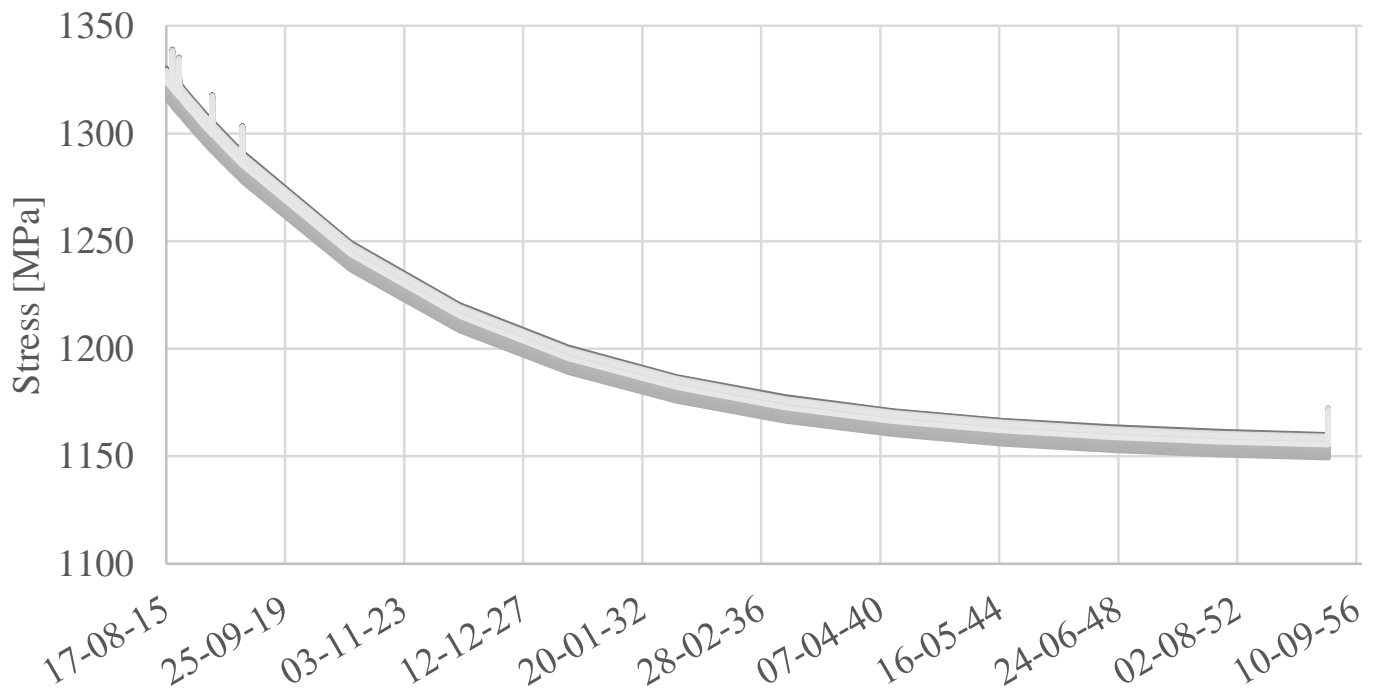

Figure 22 Evolution of the prestressing force in vertical tendons for the 40-year analysis

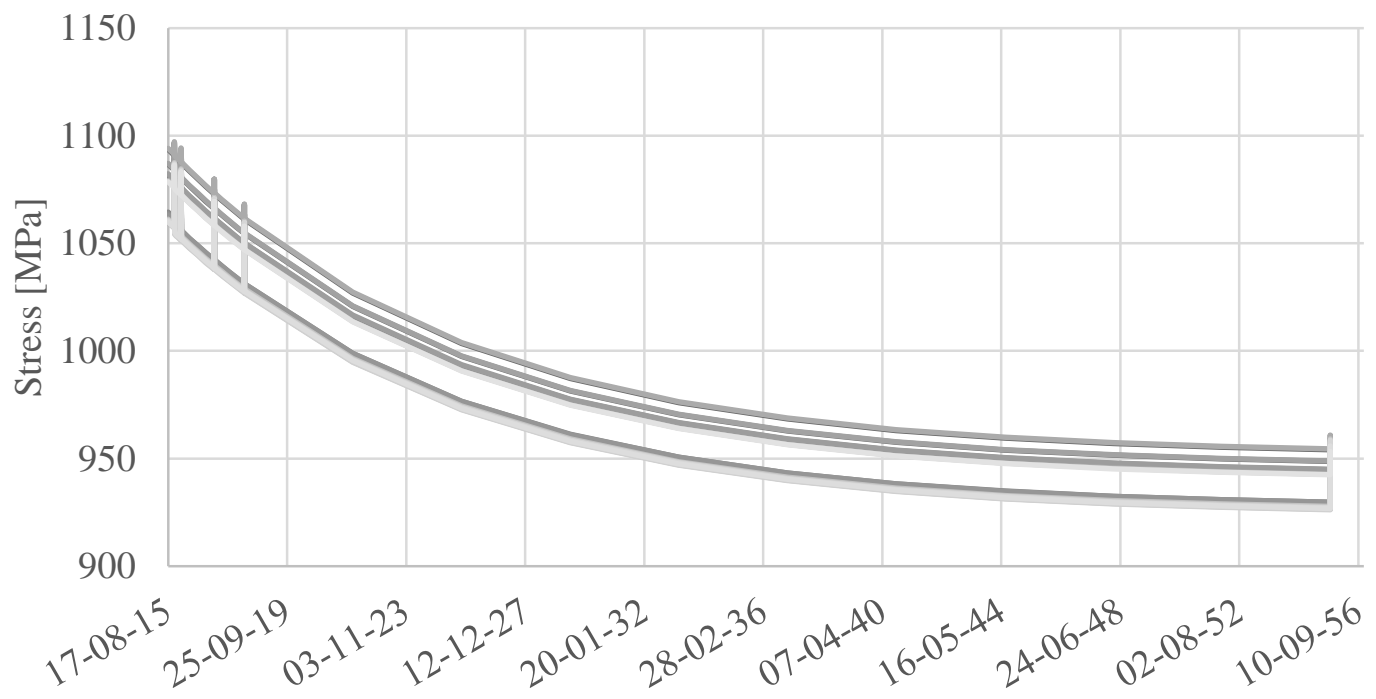

Figure 23 Evolution of the prestressing force in dome tendons for the 40-year analysis 


\section{Conclusions}

The results presented in this article provide an overview of the work done for the topic "Mechanical behaviour of the containment during the pressurization tests" of the International Benchmark VeRCoRs 2018.

The obtained results emphasize the capabilities of the Serial-Parallel Rule of Mixtures (S-P RoM) to predict properly the experimental results obtained by VeRCoRs, although there is still room for the improvement of this approach. The main advantage of the applied technique is related to its nature as manager of constitutive models, which allows to reproduce the overall behaviour of the structure by properly selecting the constitutive laws that better capture the response of the component materials. By doing this, results are obtained for each simple material. This is something that is not always possible with other techniques and which is essential to totally understand the phenomena occurring during the life of the structure and also helps in the prediction and treatment of possible malfunctions. Therefore, the S-P RoM postulates itself as an adequate tool for the analysis of nuclear containment buildings.

The applied numerical approach captures reasonably the real behaviour of the containment building, reproducing correctly the pressure tests which have been performed. Although only strain results have been susceptible to be compared with the experimental records, the results presented for the other variables also show a coherent evolution that suggest a proper fit with the real structural behaviour.

\section{Acknowledgments}

This work has been done within the framework of the VeRCoRs project. The computational method used in this paper arose from the collaboration between CIMNE and the Asociación Nuclear Ascó-Vandellós II (ANAV) during the project ANAV 16BCX1000154. The work has been also supported by the Spanish Government program FPU: FPU16/02697 and FPU17/04196 and by the AVINT project, grant no. COMRDI16-1-0019-08. The authors gratefully acknowledge all the received support.

\section{References}

[1] Électricité de France (EDF). Vercors project eDF. URL https://fr.xing-events.com/OLDEDF-vercors-project.html?page $=1320865$

[2] A. Cornejo, L.G. Barbu, C. Escudero, X. Martínez, S. Oller and A.H. Barbat. Methodology for the analysis of post-tensioned structures using a constitutive serialparallel rule of mixtures, Composite Structures, Volume 200, 2018, Pages 480-497, ISSN 0263-8223.

[3] Barbu, L.G.; Escudero, C.; Cornejo, A.; Martinez, X.; Oller, S.; Barbat, A. H. Analysis of pre-tensioned structures by means of a constitutive Serial-Parallel rule of mixtures. International Conference on Computational Plasticity. "Computational Plasticity XIV: Fundamentals and Applications: proceedings of the XIVInternational Conference on Computational Plasticity: Fundamentals and Applications, held in Barcelona, Spain 5-7 September 2017". Barcelona: 2017, p. 471-482.

[4] Martinez, X.; Oller, S.; Rastellini, F. Análisis no-lineal de materiales compuestos mediante la teoría de mezclas serie-paralelo, 2014, 10.3926/oms.208.

[5] Rastellini F. Modelización numérica de la no-linealidad constitutiva de laminados compuestos, May 2006.

[6] Barbu, L.; Cornejo, A.; Martinez, X.; Oller, S.; Barbat, A. Methodology for the analysis of post-tensioned structures using a constitutive serial-parallel rule of mixtures: large scale non-linear analysis. Composite structures, May 2019, vol. 216, p. 315-330.

[7] Jiménez, S.; Barbu, L.; Oller, S. Analysis of post-tensioned structures by means of a constitutive serial-parallel rule of mixtures, Monograph CIMNE (2018). M178 URL https://www.scipedia.com/public/Jimenez_et_al_2018a 
[8] PLastic Crack dynamic. URL http://www.cimne.com/PLCd

[9] Barbat, A.H.; Cervera, M.; Hanganu, A.; Cirauqui, C.; Oñate, E. Failure pressure evaluation of the containment building of a large dry nuclear power plant, Nuclear Engineering and Design, 180 (1998) 251 - 270.

[10] Oller, S. Nonlinear Dynamics of Structures, Springer, CIMNE, Barcelona, Spain, 2014. ISBN: 978-3-319-05193-2 (HB)

[11] Oliver, J., Cervera, M., Oller, S., and Lubliner, J. Isotropic damage models and smeared crack analysis of concrete, In Second international conference on computer aided analysis and design of concrete structures 1990; 2:945-58.

[12] Oller, S. Un modelo de daño continuo para materiales friccionales, Barcelona (1988).

[13] Barbu, L.G.; Oller, S.; Martinez X.; Barbat, A.H. High cycle fatigue simulation: a new stepwise load-advancing strategy. Engineering structures, August 2015, vol. 97, p. 118129.

[14] Barbu, L.G.; Oller, S.; Martinez, X.; Barbat, A.H. High-cycle fatigue constitutive model and a load-advanced strategy for the analysis of unidirectional fiber reinforced composites subjected to longitudinal loads. Journal of Composite Structures, 220:622641. 2019.

[15] Ministerio de Fomento. EHE-08. Instrucción de Hormigón Estructural, 2011.

[16] European Committee for Standardization. Eurocode 2: Design of concrete structures Part 1-1: General rules and rules for buildings, 2004.

[17] Marí, A. R.; Aguado, A.; Agulló, L.; Martínez, F.; Cobo, D. Hormigón armado y pretensado: ejercicios: adaptado a la instrucción EHE. Barcelona: Edicions UPC, 1999. ISBN 8483013029.

[18] Murcia, J.; Aguado, A.; Marí, A. R. Hormigón armado y pretensado - I. Barcelona: Edicions UPC, 1993. ISBN 847653356X.

[19] GiD the personal pre and post processor. URL https://www.gidhome.com/ 